\title{
Upper-Level Mediterranean Oscillation index and seasonal variability of rainfall and temperature
}

\author{
Dario Redolat ${ }^{1,2, *}$, Robert Monjo ${ }^{1,3}$, Joan A. Lopez-Bustins ${ }^{4}$, Javier Martin-Vide ${ }^{4}$ \\ ${ }^{I}$ Climate Research Foundation (FIC), Madrid, Spain \\ ${ }^{2}$ Earth Physics, Astronomy and Astrophysics II, Complutense University of Madrid, \\ Madrid, Spain \\ ${ }^{3}$ Department of Algebra, Geometry and Topology, Faculty of Mathematics, \\ Complutense University of Madrid, Madrid, Spain. \\ ${ }^{4}$ Climatology Group, Department of Geography, University of Barcelona (UB), Spain \\ *Correspondence: dario@ficlima.org
}

IMPORTANT: This is a post-peer-review, pre-copyedit version of the article: Redolat D, Monjo R, Lopez-Bustins JA and Martin-Vide J. 2019. Upper-Level Mediterranean

Oscillation index and seasonal variability of rainfall and temperature, published in Theoretical and Applied Climatology. The final authenticated version is available online at http://dx.doi.org/10.1007/s00704-018-2424-6.

\begin{abstract}
The need for early seasonal forecasts stimulates continuous research in climate teleconnections. The large variability of the Mediterranean climate presents a greater difficulty in predicting climate anomalies. This article reviews teleconnection indices commonly used for the Mediterranean basin and explores possible extensions of one of them, the Mediterranean Oscillation index (MOi). In particular, the anomalies of the geopotential height field at $500 \mathrm{hPa}$ are analyzed using segmentation of the Mediterranean basin in seven spatial windows: three at eastern and four at western. That is, different versions of an Upper-Level Mediterranean Oscillation index (ULMOi) were calculated, and monthly and annual variability of precipitation and temperature were analyzed for 53 observatories from 1951 to 2015 . Best versions were selected according to the Pearson correlation, its related $p$-value, and two measures of standardized error. The combination of the Balearic Sea and Libya/Egypt windows was the best for precipitation and temperature, respectively. The ULMOi showed the highest predictive ability in combination with the Atlantic Multidecadal Oscillation index (AMOi) for the annual temperature throughout the Mediterranean basin. The best model built from the indices presented a final mean error between $15 \%$ and $25 \%$ in annual precipitation for most of the studied area.
\end{abstract}

\section{Introduction}

The weather and its variability are challenges in the development and adaptation of human beings in the natural environment. Forecasting the weather has presented great difficulties from the first attempts in the 1920s until the development of numerical modeling and computation (Lynch 2008). Although there have been great improvements in numerical weather prediction for both weather and climate over the last century, there is still great uncertainty, which is even greater in seasonal forecasting, a field that is somewhere between meteorology and climatology. Therefore, seasonal forecasting has had a less advanced development and is thus less reliable.

In global and regional seasonal forecasting, most of the teleconnection indices can serve as predictive tools according to their ability to explain the climatic variability of a 
region, especially when these are influenced by ocean circulations. The study of the statistical correlation between two points allows us to generate and improve simulation models, which are capable of making forecasts in the medium and long terms with greater reliability. In addition to the difficulty of these simulations, the great geographical and meteorological complexity of the Mediterranean basin presents an added challenge (Lopez-Bustins et al. 2008a). Thus, it is necessary to continue researching and optimizing these teleconnection indices.

Usually, teleconnection indices were defined either as anomalies of a climatic variable, using the difference between two geographical points, or as principal components (Hurrell 1995; López-Bustins et al. 2008b; Criado-Aldeanueva and SotoNavarro 2013). The most widely used index for the Mediterranean basin is the Mediterranean Oscillation index (MOi), but there are different versions, depending on the points of reference (Criado-Aldeanueva and Soto-Navarro 2013). Conte et al. (1989) defined, as the standardized MOi of $500 \mathrm{hPa}$, the difference between the geopotential heights of Algiers $\left(36.4^{\circ} \mathrm{N}, 3.1^{\circ} \mathrm{E}\right)$ and Cairo $\left(30.1^{\circ} \mathrm{N}, 31.4^{\circ} \mathrm{E}\right)$. Later versions were calculated based on differences in sea level pressure (Palutikof et al. 1996). For example, Palutikof (2003) later took the differences between Gibraltar $\left(36.1^{\circ} \mathrm{N}, 5.3^{\circ} \mathrm{W}\right)$ and Lod Airport (Israel) $\left(32.0^{\circ} \mathrm{N}, 34.5^{\circ} \mathrm{E}\right)$. Brunetti et al. (2002) designed a specific MOi version for the central Mediterranean using the difference between the normalized sea level pressure of Marseille and that of Jerusalem. This index has a good statistical correlation with the total rainfall and the number of wet days in Italy (Brunetti et al. 2002). Papadopoulos et al. (2012a, 2012b) introduced a version based on the difference between sea level pressure in southern France $\left(45^{\circ} \mathrm{N}, 5^{\circ} \mathrm{E}\right)$ and the Levantine Sea $\left(35^{\circ} \mathrm{N}, 30^{\circ} \mathrm{E}\right)$. Another notable index is the Western Mediterranean Oscillation index (WeMOi) (MartinVide and Lopez-Bustins 2006), which is defined by sea level pressure (SLP) difference between Padua (Italy) and San Fernando (Spain). Other indices outside the basin are of interest to show the influence of other global circulations over the Mediterranean itself, such as the Arctic Oscillation index (AOi) (Thompson and Wallace 1998), the North Atlantic Oscillation index (NAOi) (Hurrell 1995; Scaife et al. 2014), the Atlantic Multidecadal Oscillation index (AMOi) (Schlesinger 1994; O'Reilly et al. 2016), El Niño Southern Oscillation index (ENSOi) (Trenberth and Stepaniak 2001), the Pacific Decadal Oscillation (PDOi) (Zhang et al. 1997), the Sahel Precipitation Index (SAHEL-Pi) (Mitchell 2016), or the Gulf Stream north wall index (GSNWi) (Taylor 2011), among others.

Regarding the original idea of MOi, which was defined for the level of $500 \mathrm{hPa}$ (Conte et al. 1989), this article explores possible extensions of this definition and contrasts a set of combinations based on different areas of the Mediterranean basin. The novel proposal of this work is the use of areas instead of isolated points, contrasting with the definition of the MOi. In addition, the idea of using the medium-upper level of the troposphere was recovered, particularly taking $500 \mathrm{hPa}$ geopotential height. Thus, the new version suggested here is the Upper-Level Mediterranean Oscillation index (ULMOi).

The purpose of the MOi extension is found in the interaction of the general atmospheric circulation in the northern hemisphere with that of the Mediterranean, driven by geographical features of irregular shapes and sizes. However, when an interaction occurs, it then generates a partial coupling stationary Rossby wave whose length is between 5,000 and 10,000 km (Wells 2011). Because of this partial coupling of the Rossby wave with the length of the Mediterranean Sea, diverse (often opposed) types of weather are generated along the Mediterranean basin. This diversity has motivated many researchers to use teleconnection indices to study the synoptic climatology or other 
environmental components over the Mediterranean basin (Milošević 2016; Izquierdo et al. 2015; Plumb 2003; Maheras et al., 1999a,b).

Therefore, the paper is structured around the design of the new index. In Section 2, we describe the study area, meteorological data, and the definition of the different versions of the ULMOi. In Section 3, we present results for precipitation and temperature variability, the variance explained by the ULMOi, and their relation with other teleconnection indices. Finally, in Section 4, we derive the main conclusions.

\section{Data and methodology}

\subsection{Study area and data}

This study focused on specific regions of the Mediterranean basin. We specifically arranged seven spatial windows: three located along the Iberian Peninsula (A, B, and C) and the remaining four over the central and eastern Mediterranean (1-4) (Figure 1 and Table 1). As representative points of climate variability in the Mediterranean basin, 53 observatories located throughout the Mediterranean basin and vicinity were selected (see Appendix, Table A1).

In particular, monthly and annual meteorological data were used from 40 thermopluviometric series, 4 precipitation series, and 10 temperature series (see Appendix). The study period is 1951-2015 (65 years). The data of 42 observatories were provided by the European Climatic Assessment and Dataset (ECA\&D, 2017), 9 observatories from the Global Historical Climatology Network (GHCN), and 2 from the Global Summary of the Day (GSOD) datasets. Furthermore, indices data were provided by Climate Research Unit of East Anglia University (CRU 2017) for MOi; National Oceanic and Atmospheric Administration (NOAA 2017) for NAOi, ENSOi, AMOi and AOi; Joint Institute for the Study of the Atmosphere and Ocean (JISAO 2017) for PDOi and SAHEL-Pi; Taylor (2011) for GSNWi; and University of Barcelona (UB 2017) for WeMOi.

Quality control was performed based on a daily homogeneity test (Monjo et al. 2013). In case of inhomogeneities, the longest homogeneous part was considered. Only observatories with less than $25 \%$ of gaps in at least 10 years have been used in this study. For temperature, 42 observatory datasets were downloaded from ECA\&D, 12 from the GHCN, and 5 from GSOD of which only 40, 9 and 2 passed the filter, respectively.

For precipitation, 40 observatory datasets were downloaded from ECA\&D and 12 from the GHCN of which, respectively, only 35 and 8 passed the filter.

In addition to the observed time series, the NCEP/NCAR reanalysis was used in this study (see Section 2.2.2.) (e.g., Kalnay et al. 1996; Kistler et al. 2001). In particular, $500 \mathrm{hPa}$ geopotential height anomalies were calculated at monthly scale for each of the seven spatial windows.

\subsection{Methodology}

\subsubsection{Teleconnection indices}

To analyze the atmospheric oscillations of the Mediterranean, we first considered the WeMOi and the MOi. These indices are calculated at a surface level according to MartinVide and Lopez-Bustins (2006) and Conte et al. (1989), respectively, using as points of reference San Fernando (Spain) and Padua (Italy) for the WeMOi, and Algiers (Algeria) and Cairo (Egypt) for the MOi. Conte et al. (1989) found that the MOi implies a dipole pattern, especially at upper levels (e.g., $500 \mathrm{hPa}$ ). However, MOi was proposed by Palutikof (2003) using SLP because of the availability of older surface observed data. 
The study considered other indices of external origin to the Mediterranean basin, such as the ENSOi, PDOi, NAOi, AOi, AMOi, SAHEL-Pi and GSNWi (Table 2). In order to analyze the role of the polar jet stream as an energy distributor at high and middle latitudes (affecting the Mediterranean basin), two measurements were taken into account: first, the averaged Global Jet Stream Latitude (GJSL), obtained from the maximum wind at $300 \mathrm{hPa}$ between $45^{\circ} \mathrm{N}$ and $90^{\circ} \mathrm{N}$; and second, due to geographical proximity, an Atlantic Jet Stream Latitude (AJSL) that was computed like GJSL, but bounded between $4^{\circ} \mathrm{W}$ and $53^{\circ} \mathrm{W}, 45^{\circ} \mathrm{N}$ to the North Pole.

\subsubsection{ULMOi design}

As a new development for this paper, we extended the original definition of MOi related to the middle and upper levels of the troposphere, namely ULMOi. In particular, the anomalies of geopotential height at $500 \mathrm{hPa}$ (from NCEP/NCAR reanalysis) were taken into account. ULMOi was defined as the standardized anomaly between $500 \mathrm{hPa}$ height of the west (windows A, B, and C) and east (windows 1 to 4 )

$$
U L M O i_{w e}=\frac{D 500_{w e}-\left(\overline{D 500_{w e}}\right)}{\sqrt{\frac{\sum_{i=1}^{N}\left(D 500_{w e}-\left(\overline{D 500_{w e}}\right)\right)^{2}}{\mathrm{~N}-1}}}
$$

where D500 we is the difference between $500 \mathrm{hPa}$ height of the western (w) and eastern (e) windows. Note that an alternative way to define a dipolar index is to introduce an additional standardization for each side (western and eastern) before taking the difference, but in this case, it was statistically indistinguishable due to use of similar latitudes in both sides (Jones et al. 1997).

To check the best selection of the western and eastern side, we considered a total of seven windows spatially distributed throughout the Mediterranean basin: three in the western basin and four in the eastern basin center (Figure 1). The idea of using areas instead of points is double: On the one hand, this allows an almost independence concerning the spatial resolution of the used grid, and on the other hand, it allows capture of the synoptic variability of D500ab through a few strategic windows, related with the Rossby wave. In fact, a half stationary Rossby wave tends to coincide with the amplitude of the Mediterranean basin (Wells 2011). This pattern generates a statistically inverse correlation of temperature and atmospheric pressure between both sides of the Mediterranean basin (Conte et al., 1989). Although the Rossby wave does not always fit perfectly in the Mediterranean basin, a partial coupling is observed (see Sec. 3.4).

The general segmentation of the Mediterranean basin can be explained by the inverse correlation found, for daily $500 \mathrm{hPa}$ height anomalies, between the western and eastern basin $(R=-0.3$, p-value $<0.001)$. More specifically, the western basin windows are justified by a common pattern: the rainiest episodes in the western Mediterranean have a predominance of maritime flows with the presence of blocking configurations with areas of low pressure near the Iberian Peninsula (A), Strait of Gibraltar (B), or the Balearic Sea (C) (Martin-Vide et al. 2008). Meanwhile, oriental segmentation is explained by searching of possible Rossby wave couplings, with a mean wavelength of $5000 \mathrm{~km}$ or lower than the Mediterranean basin length (between the Iberian Peninsula and the eastern basin sector). Taking into account the most dipolar sides at $500 \mathrm{hPa}$ (estimated using the inverse correlation in $500 \mathrm{hPa}$ height), the windows 3 and 4 are arranged around the eastern side of the dipole. Windows 1 and 2 are arranged around the central and eastern sector to check if there is also a combination that shows statistical correlation. 
These windows were considered as two control areas to contrast with the 3 and 4 , which are expected to be the optimum windows.

Therefore, geographical segmentation in the seven windows is due to the need to identify possible patterns of statistical correlation of precipitation and temperature along the Mediterranean. As a result, twelve versions of ULMOi, from combinations of three western and four eastern windows, were designed and tested. The best version was selected according to a detrended analysis with different statistical measures such as Pearson's correlation coefficient (R), the dependence $\mathrm{p}$-value (linear regression), and two measures of predictive ability (or skill score) according to the standardized absolute error (SAE) and the standardized mean squared error (SSE):

$$
\begin{gathered}
S A E=\frac{\sum_{i=1}^{N}\left|s_{i}-o_{i}\right|}{\sum_{i=1}^{N}\left|\bar{o}_{i}-o_{i}\right|} \\
S S E=\sqrt{\frac{\sum_{i=1}^{N}\left(s_{i}-o_{i}\right)^{2}}{\sum_{i=1}^{N}\left(\bar{o}_{i}-o_{i}\right)^{2}}}
\end{gathered}
$$

where $s_{i}$ is the simulation, $o_{i}$ is the observation, and $\bar{o}_{i}$ is the mean of the observations. The denominator of these measures represents the reference error of a prediction performed using the mean climatology $\left(\overline{\mathrm{o}}_{i}\right)$. Note that the explained variance (VE) is related with the SSE as VE $=1-\mathrm{SSE}^{2}$.

To rank the twelve versions of ULMOi according to ability, a fractional order $(F O)$ was assigned using two steps:

1. Linear ordering: For each statistical measure, a value of 1 for the best version of ULMOi and a value of twelve for the worst version were assigned. Other versions were evaluated linearly from one to twelve according to the distance to the best and worst version.

2. Final average: The above process was repeated for each month of the year and the arithmetic mean was calculated for each observatory. Thus, if a version obtained an average equal to one or twelve, respectively, it means that was the first or last of all statistical tests.

Thus, if we denote as $E_{i j}$ to the $j$-statistic (SSE, SAE, $1-\mathrm{R}^{2}$, and p-value) of the $i$ version (12 in total) of ULMOi, the fractional order $F O_{i j}$ associated with this statistic is

$$
F O_{i j}=1+11 \frac{E_{i j}-\min _{1 \leq i \leq 12}\left(E_{i j}\right)}{\max _{1 \leq i \leq 12}\left(E_{i j}\right)-\min _{1 \leq i \leq 12}\left(E_{i j}\right)}
$$

Note that $E_{i j}$ are elements of a matrix of 12 rows (for the possible versions of ULMOi) and 4 columns (for the used statistical measures). Therefore, the fractional order $F O_{i}$ of the $i$-version ULMOi, considering 4 statistical measures $\left(E_{i j}, j=1, \ldots, 4\right)$, is

$$
\mathrm{FO}_{\mathrm{i}}=\frac{1}{4} \sum_{\mathrm{j}=1}^{4} \mathrm{FO}_{\mathrm{ij}}
$$

\subsubsection{Analysis of the ULMOi variability}

Causes of climate variability were sought according to several versions of ULMOi. For this purpose, the temporal trend was eliminated in all indices, so they became stationary time series. Thus, prediction sensitivity was analyzed. Anomalies of temperature and precipitation at the 45 stations were computed as stationary on annual and monthly scales 
for the entire study period. Finally, two optimal versions of the ULMOi were obtained to explain, respectively, the anomalies of temperature and precipitation.

The possible interdependence of teleconnection indices considered in this study (Table 2) was analyzed by simple backward stepwise-regression based on the Akaike Information Criterion (AIC) (Efroymson 1960; Hastie and Pregibon 1992; Venables and Ripley 2002). Furthermore, the statistical significance of the Pearson correlations (R) between the different indices was examined. To measure the significance and the predictive ability of the linear models, an analysis of variance (ANOVA) (Spiegel et al. 2007) was considered using their $p$-values. According to the results of the interdependence of the indices, an optimal combination for prediction of the temperature and precipitation anomalies is proposed. Nevertheless, it is remarkable that a no significant $p$-value only implies that there is not linear interdependence, but there may be highly complex nonlinear relationships that will not be studied in this paper.

To analyze the possible periodicity of the quasi-oscillation ULMOi, we performed the spectral density (periodogram) with the fast Fourier transform (FFT) (Venables and Ripley 2002). Finally, an accurate analysis was carried out on the prevailing weather patterns and physical connections to weather types that cause climatic anomalies.

Additionally, synoptic situations were classified according to the optimal version of ULMOi, from which three situations were considered at daily scale: positive phase (ULMOi > 0.5), negative phase (ULMOi < -0.5$)$, and neutral phase $(-0.5<$ ULMOi < $0.5)$.

\section{Results and discussion}

\subsection{Design of ULMOi for precipitation}

For all the points analyzed, the pair of windows that presents the highest statistical and most significant correlation (most with $p$-value < 0.05) between prediction and observation of the annual precipitation corresponds to the $\mathrm{C} 4, \mathrm{~A} 4$, and $\mathrm{A} 3$ windows (Figure 2).

The places with the most significant $p$-value for annual precipitation, according to the ULMOi, are Madrid, Milan, Bilbao, A Coruña, and Toulouse (Figure 3). For winter, higher variance explained of all versions of ULMOi is detected in all observatories. Specifically, those with the best results are Lisbon, Madrid, Badajoz, Zaragoza, and Malaga. In spring, the lowest $p$-values correspond to the Bilbao, Milan, Madrid, Genoa, and Toulouse stations. Otherwise, the worst values for all stations are generally observed during the summer. However, some observatories have $p$-values $<0.05$, as in the case of Toulouse, Bilbao, Lyon, and A Coruña. During autumn, stations that present the highest explained variance are Milan, Toulouse, Bilbao, Madrid, and Zagreb (Figure 3).

The ULMOi version that has the highest explained variance of precipitation is the C4: i.e., calculated with the Balearic Sea-North Libya (Figure 1). This is coherent with its best fractional order (see Appendix, Table A2). From the Pearson correlation coefficient calculated for this, the anomaly precipitation sign for every observatory in the Mediterranean basin was identified in relation to the ULMOi (Figure 4). In the northwest basin, relations with widely spread negative signs are observed, with a Pearson correlation of up to 0.5 being the most statistically significant. On the other hand, the eastern Mediterranean has no statistically significant relationships, although they are negative in Greece and positive in winter months in some isolated points such as Latakia, Jerusalem, or Mersa-Matruh. A similar spatial pattern is found throughout the year, interrupted only in summer months, with neutral or positive values in the east (Figure 4). Note that the 
Jerusalem and Cairo stations are not shown in July and August, and June and July respectively, because no precipitation was recorded during the analyzed period.

This observed spatial distribution of correlation coefficients is caused by atmospheric blockings (which generate high pressure over the Iberian Peninsula) over the Mediterranean basin in the positive phase of the ULMOi, producing negative vertical velocities that inhibit the largely favorable upward movement to generate precipitation (Holton J. 1972). However, the more eastward in the basin, the weaker this atmospheric blocking becomes. Because of this, we find negative values or slightly positive ones without statistical significance in these regions. This pattern is consistent with patterns found by other authors (Maheras et al., 1999a,b, Tornos 2013). Nevertheless, we also find negative values with high statistical significance in the southeast or neutral values in the westernmost regions. This heterogeneity over the southeastern basin with a given value of ULMOi seems to be due mainly to geographical causes, wind regimes which favor precipitation, windward/leeward side to humid/dry air masses, orographic barriers, or other factors (González-Hidalgo et al. 2009, Cortesi et al. 2012).

The ability level to predict precipitation obtained with error measurements is similar for SAE and SSE. Note that all values of SSE are lower than unit (Figure 5). That is, all predictions commit errors lower than reference prediction based on the climatic average. According to these error measurements, some cases with high-explained variance appear again in the central and eastern swathes, such as Palermo, Kalamata, Sirte, and Latakia. We observe this to a lesser extent in the western basin in the Spanish cities of Madrid, Palma, and Malaga.

\subsection{Design of ULMOi for temperature}

For all temperature stations, the pair of windows that has a highest statistical correlation (and lowest $p$-values) between prediction and observation for annual temperature corresponds to $\mathrm{C} 3$, followed by $\mathrm{C} 4$, and, in third place, $\mathrm{C} 2$ and $\mathrm{A} 3$ which are statistically equivalent (Figure 6). Similar results were found according to the fractional order (see Appendix, Table A3).

As for the annual temperature, our research shows statistically significant values ( $p$-value < 0.05 ) for most versions of ULMOi, especially for the following observatories: Siwa, Mersa-Matruh, Lebanese Tripoli, Agedabia, and Madrid (Figure 7). In fact, for the annual estimation, there is no single version of ULMOi that stands out from the others (see Appendix). During the winter, most stations have better results than in the annual values, especially in eastern basin stations such as Lebanese Tripoli, Mersa-Matruh, Siwa, Sirte, and Agedabia. Palermo is the station that presents the worst statistics for winter temperature. In spring, the Badajoz, Lisbon, Madrid, Zaragoza, Lebanese Tripoli, and Barcelona stations have a better statistical fit. In summer, some stations have a very high statistical correlation between values predicted by ULMOi and observations; among these are Madrid, Zaragoza, Badajoz, Barcelona, Lisbon, and Perpignan. Meanwhile, autumn shows very significant $p$-values for most stations in windows A and 3 (the Iberian Peninsula and the eastern Mediterranean) (Figure 7).

Once identified, for the windows which have higher explained variance for temperature (C3: Balearic Sea-Levantine Sea), Pearson's correlation for all the basin observatories was analyzed and outstanding results were obtained (Figure 8). First, the western Mediterranean, formed by the Iberian Peninsula, Morocco, and Algeria, along with Croatia and central regions such as northern Italy, have positive correlations, most of which are statistically significant (Pearson correlation up to 0.6). The inverse correlation occurs in the central and northeastern Mediterranean (the Levant, Turkey, and 
Libya). In the case of Greece, we see negative values during most of the year, while they are significantly positive at the end of spring. We found statistically significant negative values in Jerusalem, Heraklion, and Sirte, among other observatories. A strong correlation dipole between eastern and western basin is observed during the spring and autumn seasons, but is weaker or disappears in winter and summer. A positive ULMOi means higher geopotential in the western Mediterranean. This result implies that geopotential is more likely to have positive $500 / 1000 \mathrm{hPa}$ thickness and positive temperature anomalies by hydrostatic equilibrium. This pattern is similar to the one found by Maheras et al., (1999a,b).

As with the prediction of precipitation, the ability to predict temperature is adequate according to the SAE and SSE measurements. Similarly, all values are lower than the SSE unit (Figure 9) and, therefore, errors will be lower than a prediction based on the reference climate average. According to these error measures, there are stations with highexplained variance (SSE between 0.6 and 0.8 ) in the central area and the Levant of the Mediterranean: Thessaloniki, Lamia, Izmir, Siwa, Mersa-Matruh, and others. Some observatories in the extreme west, such as Palma, Ceuta, and Madrid, also present acceptable errors, improving prediction by up to $10 \%$.

\subsection{Comparison with other indices}

The comparison with other indices was analyzed for the best versions of the ULMOi. According to the $p$-values of that comparison, the simulation of annual rainfall is better with ULMOi followed by MOi (Figure 10, right). For annual temperature, AMOi gets the best result, nearly matched by ULMOi (Figure 10, left) with $p$-value $<0.05$ for more than half the stations (note that maximum $p$-values of ULMOi are lower than the maximum of AMOi).

There is no statistically significant correlation between ULMOi and AMOi and, as both are good predictors for temperature, their combination shows a good performance in the multiple regression ULMOi ranks as the second-best predictor of annual temperature when it is combined with the other one (AMOi). The final error of the annual temperature prediction with ULMOi combined with AMOi is between $0.3{ }^{\circ} \mathrm{C}$ and $0.6{ }^{\circ} \mathrm{C}$, corresponding to an SSE between 0.7 and 0.9.

Although MOi and ULMOi are good individual predictors for precipitation, there is a very significant correlation between them ( $p$-value $<0.001, R=0.5$ ), which causes its predictive ability to be shared among them in multiple regression. Hence, the final error for annual precipitation is $15 \%-25 \%$, which corresponds to an SSE of 0.8 to 0.9 .

ENSOi and GSNWi obtained the worst results separately (simple regression) for the explanation of the variance of annual anomalies of temperature and precipitation respectively) (Figure 10). Meanwhile, NAO and GSNW obtained the worst results together (multiple regression, for temperature and precipitation respectively).

For simple regression ENSOi has predictive capability for temperature in only two of the cases analyzed (Nicosia and Zaragoza); GSNWi in six cases for precipitation (Dubrovnik, Bilbao, Rome, Malaga, Cagliari, and Madrid). In multiple regression, the NAOi is also capable of explaining the variance of temperature in one case (Finike) and for GSNWi in precipitation is good in three cases (Bilbao, Malaga, and Rome). The poor results of the NAOi and ENSOi found for the Mediterranean basin contrasts with their high ability for seasonal forecasting in America and Western Europe (Scaife et al. 2014).

\subsection{ULMO variability and causes}




\subsubsection{Variability}

The ULMOi showed a high temporal variability and a high level of noise. According to the FFT analysis, several ULMOi periods were distinguished. These periods range from three months to eight years, with twelve months being the most frequent due to the seasonal nature of the Rossby wave (White 2001, Hitchman and Huesmann 2007). Also, one secondary cycle ( $5 \pm 1$ months) was observed. Similarly, three multiyear cycles of $2.5 \pm 0.5,7 \pm 1$, and $25 \pm 9$ years were detected. Note that many oscillations of $2-3$ years were more frequent in the decades between 1990 and 2000, while eight-year oscillations were more typical in the decades between 1950 and 1970 (Figure 11a). Regarding to the trend analysis, ULMOi has no significant trend ( $\mathrm{p}$-value >0.05).

The phases of the ULMOi has been represented by three cases of the anomaly of the geopotential height at $500 \mathrm{hPa}$. For the positive phases a slightly positive of $0.5<$ ULMOi<1.5 deviation (Fig. 11 c), and an extreme deviation ULMO >3 (Fig. $11 \mathrm{~d}$ ) are shown. Symmetrically for the negative phases, a slightly negative $-1.5<\mathrm{ULMO}<-0.5$ (Fig. 11 e) deviation and an extreme deviation ULMO $<-3$ (Fig. $11 \mathrm{f}$ ) are shown. The synoptic analysis of the phases are:

1. Neutral phase: It is characterized by zonality of geopotential height isolines along the basin, being slightly lower in the east than in the west. Note that Figure $11 \mathrm{~b}$ shows the average of the geopotential at $500 \mathrm{hPa}$ height, which is practically identical to the neutral phase. The average is interesting because it shows the role of the surface friction on stationary wave generation, a phenomenon not exclusive to the Mediterranean basin in the northern hemisphere.

2. Positive phase (Figure 11c and 11d): It is characterized by a ridge in the Iberian Peninsula. The ridge represents high geopotential values in the west of the Mediterranean basin and low values of geopotential in the east sector (Libya, Greece, and Turkey). This scenario leads to episodes of stability and positive temperature anomalies in the western Mediterranean and negative and unstable anomalies in the east.

3. Negative phase (Fig. 11e and 11f): In this phase, the lowest values of geopotential are found in the Iberian Peninsula due to the position of a trough over it; thus, it creates unstable weather and negative thermal anomalies. By contrast, a ridge over the eastern Mediterranean is observed, causing above-normal temperatures with dry and stable weather.

It is necessary to distinguish between ULMO as a spatial wave and as a low-frequency variability pattern at long term (multi-annual oscillation) due to variations in the frequency of appearance of the spatial wave. The spatial wave is the phenomenon which frequency, intensity, and duration vary in a multi-annual scale. This variability is expected to be captured by the ULMOi, in a similar way that ENSOi, PDOi or AMOi captures the variability of sea surface temperature (SST) anomalies.

\subsubsection{Causes of the spatial wave}

The ULMO spatial wave is related to the stationary Rossby wave. The dipole shown in Figure 11 between the Iberian Peninsula and eastern Mediterranean results in a length wave of 4000-5000 km (approximately), which creates opposite types of weather between both edges. This partial coupling to the topographic basin is consistent with the length of dipoles found by other authors (Wallace et al. 1981) and also with the role that continental friction has over jet stream waves (Charney et al. 1949) and the influence that the Azores high has on the Mediterranean basin. On the other hand, for the variability of ULMOi, a 
similar wavelength during positive and negative phases was considered according to one standard deviation (see Figure 11c and 11e).

\subsubsection{Causes of the temporal variability}

The ULMOi multi-annual periodicity allows us to relate it with other indices and therefore we can determinate the causes of its variability and energy flows which affect it. However, these relations are highly nonlinear and complex, so their variability is linked to a combination of these multiple indices. ULMOi has a high positive correlation with AOi, MOi, GSNWi and PDOi ( $<0.05$ in all cases), and also a negative correlation with AJSL, but not with GJSL. Meanwhile, GJSL has a high positive correlation with most relevant SST indices (i.e., ENSOi, PDOi) and also with the WeMOi. On the other hand, AJSL has a significant negative correlation with ULMOi, GSNWi, and ENSOi for large periods (Fig. 12).

According to the AIC obtained from the backward stepwise-regression, ULMOi depends on AOi, AJSL, PDOi and AMOi (Fig. 12). This dependence could explain the origin of the ULMO multi-annual periodicities $(2.5 \pm 0.5,7 \pm 1$, and $25 \pm 9$ years, Sec. 3.4.1), which cannot be caused by internal variability of the atmosphere. These periodicities are probably due to nonlinear connections with the energy flow variability from the Pacific and Atlantic oceans. To check this hypothesis, we analyzed the connection nodes of PDO with GJSL/AJSL, AMO with AJSL, and AJSL with ULMO. According to the correlation analysis (Fig. 12), the multi-decadal energy flow variability is probably transferred to the ULMO according to two schemes:

$$
\begin{aligned}
& {[\mathrm{PDO} / \mathrm{ENSO}] \rightarrow[\mathrm{GJSL} \rightarrow \mathrm{AJSL} \leftrightarrow \mathrm{AO}] \rightarrow \text { ULMO }} \\
& {[\mathrm{AMO} / \mathrm{GSNW}] \rightarrow[\mathrm{AJSL} \leftrightarrow \mathrm{NAO}] \rightarrow \text { ULMO }}
\end{aligned}
$$

In fact, PDO significantly influences the GJSL (p-value < 0.001) and the AJSL (pvalue < 0.05). On the other hand, AJSL is correlated with the ULMOi (p-values < 0.05). These relations are consistent with the teleconnection Pacific-Mediterranean found by other authors (López-Parages and Rodríguez-Fonseca 2012; Muñoz-Díaz and Rodrigo 2005). Regarding the Atlantic variability modes, AMOi and GSNWi seem to have a significant influence on the ULMOi through the AJSL (p-values <0.05).

On the multiyear time scale, the sudden variations of the oceanic-atmosphere coupling, such as ENSO, can be transmitted by the jet stream (GJSL and AJSL), and also modulated by other atmospheric patterns with great influence on the Mediterranean as the AO (p-value <0.005) and NAO (p-value < 0.01), in agreement with Fedorov (2007). Therefore, an important dependence of the ULMOi on the climate variability modulated by the ocean-atmosphere coupling is observed through the variations of the jet stream over the Mediterranean, especially from the PDOi and the AMOi, modulated by ENSOi and GSNWi.

According to this and the spatial distribution of the correlation (Fig. 8), we can corroborate that the Rossby wave is coupled with the Mediterranean basin. In future works, this coupling will allow us to predict temperature and rainfall anomalies in the Mediterranean basin.

\subsection{Future works}

These results are preliminary; therefore, it is recommended to continue the analysis of the main properties of ULMOi. Following the example of other authors, it is advisable to 
examine possible changes in the frequency of each of the main modes (Ribera et al. 2000; López-Bustins et al. 2008b).

In fact, this new version of MOi opens up a possible line of research on climate variability in the Mediterranean basin. This research may help to differentiate between natural and anthropogenic contributions to climate change. For example, a significant portion of possible changes predicted for the Mediterranean are due to effects of natural variables such as seasonal NAO, according to several authors (Lopez-Bustins et al. 2008a, Krichak et al. 2014).

However, although ENSOi influence on the temperature of the oceans is globally important, it is unnoticed in the Mediterranean Sea (Alexander et al. 2002). The AOi and WeMOi may also have significantly influenced Mediterranean climate change in recent decades (Martin-Vide and Lopez-Bustins, 2006). Therefore, it will be necessary to analyze the possible effects of ULMOi on inter-annual climatic anomalies in future works and, subsequently, to analyze the effects on trends observed beyond natural variability.

\section{Conclusions}

First, teleconnection indices available for the Mediterranean were reported. Next, the need to expand the definition of MOi was determined by using an index represented by areas instead of observatories or specific points. To improve the predictability of seasonal anomalies in the Mediterranean, this work focuses on developing an index based on the differences of geopotential height at $500 \mathrm{hPa}$, which is referred to as ULMOi. For rainfall predictability, the new index has reported higher confidence than the MOi, with a p-value $<0.05$ against p-value $>0.1$, obtained by rest indices, for more than half of all stations. Furthermore, for temperature, ULMOi has the second rank behind AMOi, with p-values below 0.05 for more than half of all stations.

The physical link between ULMOi and surface temperature anomaly is positive for the western Mediterranean basin. That is, positive ULMOi implies a higher $500 \mathrm{hPa} / 1000$ $\mathrm{hPa}$ thickness over the western side with higher temperature; otherwise, it is negative for the eastern Mediterranean basin. This result confirms the partial coupling of the Rossby wave over the Mediterranean basin. As for the relationship between ULMOi and precipitation, it is negative in nearly the entire basin, except for some stations on the eastern edge. High geopotential levels around west side inhibit upward movement (which is required for precipitation), and means stable and sunny weather in these regions. This condition is primarily due to an atmospheric blocking generated in the western Mediterranean, where westerlies are reduced and storm tracks along the eastern Mediterranean are favored.

ULMOi and AMOi show the greatest ability to explain the variance of annual temperature, adequately simulating it for more than half of the observatories (with a $p$ value $<0.1$ ). For annual precipitation, the best individual predictors are ULMOi and MOi. In contrast, ENSOi and NAOi have the lowest predictive ability for the Mediterranean basin, although they are important for seasonal forecasting in America and Western Europe. The low dependence between MOi and ULMOi explains that their combination optimizes the prediction of precipitation anomalies for most of the stations, with an error between $15 \%$ and $25 \%$ (i.e., $75 \%$ of stations show an error less than $25 \%$ ).

Like the other indices, ULMOi presents a double application. First, it can contribute to the improvement of seasonal forecast. Second, it allows for the identification of a part of the climatic variability. Future enhancements to this work would consist of making a deeper analysis of the ULMOi frequency patterns and their possible relationship with the natural contribution to the climate change. 


\section{Acknowledgments}

Thanks to my tutor Belén Rodríguez Fonseca, from the Complutense University of Madrid. Thanks also to the Climate Research Unit (CRU) of the University of East Anglia and to NOAA for the data provided to conduct this study. Some authors are members of the Climatology Group (2014 SGR 300, Catalan Government) and thanks to the WEMOTOR project (CSO2014-55799-C2-1-R), funded by the Spanish Ministry of Economy, Industry and Competitiveness, generously contributed to this research. Finally we want to highlight the support received from the RESCCUE project, which has received funding from the European Research Council (ERC) under the European Union's Horizon 2020 research and innovation programme (grant agreement $\mathrm{n}^{\circ}$ 700174).

\section{References}

Alexander MA, Blade I, Newman M, Lanzante JR, Lau N-C, Scott JD (2002) The Atmospheric Bridge: the Influence of ENSO Teleconnections on Air-Sea Interaction Over the Global Oceans. J Climate 15: 2205-2231.

Brunetti M, Maugeri, Nanni T (2002) Atmospheric circulation and precipitation in Italy for the last 50 years. Int J Climatol 22:1455-1471.

Charney JG, Eliassen A (1949) A Numerical Method for Predicting the Perturbations of the Middle Latitude Westerlies. Tellus 1: 38-54.

Conte M, Giuffrida A, Tedesco S (1989) The Mediterranean Oscillation, impact on precipitation and hydrology in Italy. Proceedings of Conference on Climate, Water. Publications of the Academy of Finland, Helsinki, p. 121-137.

Cortesi N, Gonzalez-Hidalgo JC, Brunetti M, Martin-Vide J (2012) Daily precipitation concentration across Europe 1971-2010. Natural Hazards and Earth System Science, Volume 12, Issue 9, 2012, pp.2799-2810.

Criado-Aldeanueva F, Soto-Navarro FJ (2013) The Mediterranean Oscillation Teleconnection Index: Station-Based versus Principal Component Paradigms, Advances in Meteorology 2013: ID738501, doi:/10.1155/2013/738501CRU, 2017.

CRU (2017). Mediterranean Oscillation Index (MOI) data. Climate Research Unit. Link: https://crudata.uea.ac.uk/cru/data/moi/ (accessed on 31 July 2017).

ECA (2017) European Climate Assessment \& Dataset. Link: http://www.ecad.eu/dailydata/index.php (Accessed on 31 July 2017).

Efroymson MA (1960) Multiple regression analysis Mathematical Methods for Digital Computers, Ralston A. and Wilf, H. S., (eds.), Wiley, New York.

Fedorov AV (2007) Ocean-Atmosphere Coupling. Oxford Companion to Global Change. Yale University, New Haven.

González-Hidalgo JC, López Bustins JA, Stepánek P, Martín Vide J, Luís M (2009) Monthly precipitation trends on the Mediterranean fringe of the Iberian Peninsula during the second-half of the twentieth century. Int J Climatol 29:1415-1429.

Hitchman MH, Huesmann AS (2007) A Seasonal Climatology of Rossby Wave Breaking in the 320-2000-K Layer. J Atmos Sci 64:1922-1940.

Holton JR (1972) An introduction to dynamic meteorology. Academic Press, New York, $319 \mathrm{pp}$.

Hurrell JW (1995) Decadal trends in the north-atlantic oscillation: Regional temperatures and precipitation. Science 269:676-679, doi:10.1126/science.269.5224.676.

Izquierdo R, Alarcón M, Majeed HT, Periago C, Belmonte J (2015) Influence of atmospheric teleconnection patterns on airborne pollen levels in the NE Iberian Peninsula. Clim Res 66:171-183, doi: 10.3354/cr01341. 
JISAO (2017) Joint Institute for the Study of Atmosphere and Ocean http://jisao.washington.edu/data_landing (accessed on 31 July 2017).

Jones PD, Jonsson, T, Wheeler D (1997) Extension to the North Atlantic Oscillation using early instrumental pressure observations from Gibraltar and South-West Iceland. International Journal of Climatology, 17(13), 1433-1450, doi:10.1002/(SICI)1097-0088(19971115)17:13<1433::AID-JOC203>3.0.CO;2-P

Krichak SO, Breitgand JS, Gualdi S, Feldstein SB (2014) Teleconnection-extreme precipitation relationships over the Mediterranean region. Theor Appl Climatol 117:679-692.

Lopez-Bustins JA, Martin-Vide J, Sánchez-Lorenzo A (2008a) Iberia winter rainfall trends based upon changes in teleconnection and circulation patterns. Glob Planet Chang 63:171-176.

López-Bustins JA, Sánchez-Lorenzo A, Azorín-Molina C, Ordóñez-López A (2008b) Tendencias de la precipitación invernal en la fachada oriental de la Península Ibérica. In: Sigró J, Brunet M, Aguilar E. (eds.): Cambio climático regional y sus impactos. 161-171. Publicaciones de la Asociación Española de Climatología. Serie A no 6.

López-Parages J, Rodríguez-Fonseca MB (2012) Multidecadal modulation of El Niño influence on the Euro-Mediterranean rainfall. Geophys Res Lett 39: L02704, doi:10.1029/2011GL050049.

Lynch P (2008) The origins of computer weather prediction and climate modeling. J Comput Phys 227:3431-3444. doi:10.1016/j.jcp.2007.02.034.

Maheras P, Xoplaki E, Davies T, Martin-Vide J, Bariendos M. and Alcoforado MJ (1999) Warm and cold monthly anomalies across the Mediterranean basin and their relationship with circulation; 1860-1990. Int J Climatol 19:1697-1715. doi:10.1002/(SICI)1097-0088(199912)19:15<1697::AID-JOC442>3.0.CO;2-S.

Maheras P, Xoplaki E, Kutiel H (1999) Wet and dry monthly anomalies across the Mediterranean basin and their relationship with circulation, 1860-1990. Theor Appl Climatol 64:189-199.

Martin-Vide J, Lopez-Bustins J (2006) The western Mediteranean oscillation and rainfall in the Iberian Peninsula. Int J Climatol 26:1455-1475.

Martin-Vide J, Sánchez-Lorenzo A, Lopez-Bustins JA, Cordobilla MJ, Garcia-Manuel A, Raso JM (2008) Torrential Rainfall in Northeast of the Iberian Peninsula: Synoptic patterns and WeMO influence. Advances in Science and Research, 2:99-105.

Milošević D, Savić S, Pantelić M, et al. (2016) Variability of seasonal and annual precipitation in Slovenia and its correlation with large-scale atmospheric circulation. Open Geosciences, 8(1), pp. 593-605. doi:10.1515/geo-2016-0041.

Mitchell, T. (2016) Sahel precipitation index, Joint Institute for the Study of the Atmosphere and Ocean, Univ. of Washington, doi:10.6069/H5MW2F2Q. Link: http://research.jisao.washington.edu/data_sets/sahel/ (accessed on 31 July 2017).

Monjo R, Pórtoles J, Ribalaygua J (2013) Detection of inhomogeneities in daily data: a test based in the Kolmogorov-Smirnov goodness-of-fit test. 9th Data Management Workshop of EUMETNET, El Escorial, Madrid.

Muñoz-Díaz D, Rodrigo FS (2005) Influence of the El Niño-Southern Oscillation on the probability of dry and wet seasons in Spain. Clim Res 30:1-12.

NOAA (2017) Climate Indices. Enlace: http://www.esrl.noaa.gov/psd/data/ climateindices/list/ (accessed on 31 July 2017).

O'Reilly CH, Huber LM, Woollings T, Zanna L (2016) The signature of low-frequency oceanic forcing in the Atlantic Multidecadal Oscillation. Geophys Res Lett 43. doi:10.1002/2016GL067925. 
Papadopoulos VP, Kontoyiannis H, Ruiz S, Zarokanellos N (2012a) Influence of atmospheric circulation on turbulent air-sea heat fluxes over the Mediterranean Sea during winter. J Geophys Res C, 117: C03044.

Papadopoulos VP, Josey S, Bartzokas A, Somot S, Ruiz S, Drakopoulou P (2012b) Large-scale atmospheric circulation favoring deep -and intermediate- water formation in the Mediterranean Sea. J Climate 25:6079-6091.

Palutikof JP, Conte M, Casimiro Mendes J, Goodess CM, Espirito Santo F (1996) Climate and climate change. In: Brandt CJ, Thornes JB (eds): Mediterranean desertification and land use. John Wiley and Sons, London.

Palutikof JP (2003) Analysis of Mediterranean climate data: measured and modelled. In Bolle HJ (Ed): Mediterranean Climate: Variability and Trends, Springer, Berlin, Germany.

Plumb RA (2003) Atmospheric and Oceanic circulations. Class notes, Massachusetts Institute of Technology (MIT). Link: www.ccpo.odu.edu/ klinck/Reprints/PaperWebPages/plumbAtmDyn03.html. (accessed on 31 July 2017).

Ribera P, Garcia R, Diaz HF, Gimeno L, Hernández E (2000) Trends and interannual oscillations in the main sea-level surface pressure patterns over the Mediterranean, 1955-1990. Geophys. Research Letters 27: 1143-1146.

Schlesinger ME (1994) An oscillation in the global climate system of period 65-70 years. Nature 367:723-726. doi:10.1038/367723a0.

Scaife AA, et al. (2014) Skillful long-range prediction of European and North American winters, Geophys. Res. Lett., 41, 2514-2519, doi:10.1002/2014GL059637.

Spiegel MR, Schiller J, Srinivasan RA (2007) Análisis de la varianza. Probabilidad y Estadística [Schaum's Outline of Theory and Problems of Probability and Statistics]. Schaum (2 $2^{\text {nd }}$ edition). México D.F.: McGraw-Hill. pp. 335-371. ISBN 978-970-104231-1.

Taylor, AH (2011) The Dance of Air and Sea: How Oceans, Weather and Life Link Together. Oxford University Press, 288 pp.

Törnros T (2013) On the relationship between the Mediterranean Oscillation and winter precipitation in the Southern Levant. Atmos Sci Lett 14:287-293, doi:10.1002/as12.450.

Thompson DWJ, Wallace JM (1998) The Arctic oscillation signature in the wintertime geopotential height and temperature fields. Geophysical Research Letters 25: 12971300. doi:10.1029/98GL00950.Trenberth KE, Stepaniak DP (2001) Indices of El Niño Evolution. J Climate 14:1697-1701.

UB (2017) University of Barcelona. http://www.ub.edu/gc/2016/06/08/wemo/ (accessed on 31 July 2017).

Venables WN, Ripley BD (2002) Modern Applied Statistics with S-PLUS. Fourth edition. Springer.

Wallace, J. M., and D. S. Gutzler (1981) Teleconnections in the Geopotential Height Field during the Northen Hemisphere Winter. Mon Wea Rev 109:784-812.

Wells NC (2011) The Atmosphere and Ocean: A Physical Introduction. Wiley-Blackwell. ISBN: 978-0-470-69469-5.

White W (2001) Evidence for coupled Rossby waves in the annual cycle of the IndoPacific Ocean, J Phys Oceanogr 31:2944-2957.

Zhang Y, Wallace JM, Battis DS (1997) ENSO interdecadal variability. J Climate 10:1004-1020. 


\section{Appendix}

Geographical characteristics for all considered stations are shown in Table A1. For both annual precipitation and temperature anomalies, a fractional order of the twelve versions of the ULMOi (Tables A2 and A3) was estimated following the methodology previously described. 


\section{Tables}

Table 1. Coordinates of the combined windows selected for testing several versions of ULMOi.

\begin{tabular}{l|cccc}
\multicolumn{2}{c}{$\begin{array}{c}\text { MAXIMUM } \\
\text { LATITUDE }\end{array}$} & $\begin{array}{c}\text { MINIMUM } \\
\text { LATITUDE }\end{array}$ & $\begin{array}{c}\text { MAXIMUM } \\
\text { LONGITUDE }\end{array}$ & $\begin{array}{c}\text { MINIMUM } \\
\text { LONGITUDE }\end{array}$ \\
\hline WINDOW A & 44 & 36 & 3.31 & -10.48 \\
WINDOW B & 38 & 34 & -0.30 & -7.50 \\
WINDOW C & 42.5 & 36.5 & 4.4 & -2.20 \\
\hline WINDOW 1 & 45.2 & 34.4 & 19 & 9 \\
WINDOW 2 & 43 & 35 & 31 & 18 \\
WINDOW 3 & 38 & 28 & 37.5 & 27 \\
WINDOW 4 & 32.5 & 29 & 25.5 & 14
\end{tabular}


Table 2. Indices and their variables considered in this study (where SST is sea surface temperature, $\mathrm{P}$ represents sea level pressure, $\mathrm{R}$ is rainfall, and WS is wind speed at 300 $\mathrm{hPa})$.

\begin{tabular}{|c|c|c|c|c|c|}
\hline Index & Start & End & $\begin{array}{l}\text { Used } \\
\text { variable }\end{array}$ & Used region & Reference \\
\hline ENSOi & 1870 & 2015 & SST & $\begin{array}{l}\text { El Niño } 3.4 \\
\left(170^{\circ} \mathrm{W} \text { to } 120^{\circ}\right. \\
\text { W-EQ) }\end{array}$ & NOAA (2017) \\
\hline NAOi & 1950 & 2015 & $\mathrm{P}$ & $\begin{array}{l}\text { Ponta Delgada- } \\
\text { Reykjavik }\end{array}$ & NOAA (2017) \\
\hline $\mathrm{AOi}$ & 1950 & 2015 & $\mathrm{P}$ & $\begin{array}{l}\text { Atlantic } 20^{\circ} \mathrm{N} \text { to } \\
\text { North Pole }\end{array}$ & NOAA (2017) \\
\hline AMOi & 1870 & 2015 & SST & $\begin{array}{l}\text { Atlantic } 0^{\circ}-60^{\circ} \mathrm{N} \\
\text { and } 7.5^{\circ} \mathrm{W}-7.5^{\circ} \mathrm{E}\end{array}$ & NOAA (2017) \\
\hline MOi & 1948 & 2015 & $\mathrm{P}$ & Algiers-Cairo & CRU (2017) \\
\hline WeMOi & 1821 & 2013 & $\mathrm{P}$ & $\begin{array}{l}\text { Padua-San } \\
\text { Fernando }\end{array}$ & UB (2017) \\
\hline PDOi & 1854 & 2016 & SST & Pacific $20^{\circ} \mathrm{N}$ & JISAO (2017) \\
\hline SAHEL-Pi & 1901 & 2016 & $\mathrm{R}$ & $\begin{array}{l}\text { Africa } 8^{\circ} \text { to } \\
20^{\circ} \mathrm{N}-20^{\circ} \mathrm{W} \text { to } \\
10^{\circ} \mathrm{E}\end{array}$ & Mitchell (2016) \\
\hline GSNWi & 1966 & 2010 & SST & $\begin{array}{l}\text { Atlantic } 55^{\circ} \text { to } \\
75^{\circ} \mathrm{W}-35^{\circ} \mathrm{N}\end{array}$ & Taylor (2011) \\
\hline GJSL & 1871 & 2015 & WS & $\begin{array}{l}45^{\circ} \mathrm{N} \text { to North } \\
\text { Pole }\end{array}$ & Section 2.2.1 \\
\hline AJSL & 1871 & 2015 & WS & $\begin{array}{l}\text { Atlantic } 4^{\circ} \text { to } \\
53^{\circ} \mathrm{W}-45^{\circ} \mathrm{N} \text { to } \\
\text { North Pole }\end{array}$ & Section 2.2.1 \\
\hline
\end{tabular}


Table A1. Geographical characteristics coordinates of the 53 weather stations (sorted by longitude). MASL means meters above sea level. The type can be thermometric (T), pluviometric (P), or thermopluviometric (TP).

\begin{tabular}{|c|c|c|c|c|c|c|c|}
\hline Number & Name & Lat & Lon & MASL & Country & Type & Source \\
\hline 1 & Lisbon & 38.44 & -9.08 & 114 & Portugal & $\mathrm{TP}$ & ECA\&D \\
\hline 2 & A Coruña & 43.35 & -8.4 & 97 & Spain & $\mathrm{TP}$ & ECA\&D \\
\hline 3 & Badajoz & 38.87 & -6.97 & 185 & Spain & $\mathrm{TP}$ & ECA\&D \\
\hline 4 & Kenitra & 34.25 & -6.58 & 13 & Morocco & $\mathrm{T}$ & ECA\&D \\
\hline 5 & Ceuta & 35.88 & -5.32 & 11 & Spain & $\mathrm{TP}$ & ECA\&D \\
\hline 6 & Malaga & 36.72 & -4.41 & 16 & Spain & $\mathrm{TP}$ & ECA\&D \\
\hline 7 & Madrid & 40.41 & -3.7 & 609 & Spain & $\mathrm{TP}$ & ECA\&D \\
\hline 8 & Melilla & 35.29 & -2.94 & 47 & Spain & $\mathrm{TP}$ & ECA\&D \\
\hline 9 & Bilbao & 43.25 & -2.93 & 42 & Spain & $\mathrm{TP}$ & ECA\&D \\
\hline 10 & Murcia & 37.98 & -1.13 & 5 & Spain & $\mathrm{TP}$ & ECA\&D \\
\hline 11 & Zaragoza & 41.65 & -0.88 & 263 & Spain & $\mathrm{TP}$ & ECA\&D \\
\hline 12 & Valencia & 39.47 & -0.37 & 69 & Spain & $\mathrm{TP}$ & ECA\&D \\
\hline 13 & Toulouse & 43.59 & 1.44 & 152 & France & $\mathrm{TP}$ & ECA\&D \\
\hline 14 & Barcelona & 41.39 & 2.17 & 4 & Spain & $\mathrm{TP}$ & ECA\&D \\
\hline 15 & Palma & 39.56 & 2.64 & 4 & Spain & $\mathrm{TP}$ & ECA\&D \\
\hline 16 & Perpignan & 42.68 & 2.89 & 43 & France & $\mathrm{T}$ & ECA\&D \\
\hline 17 & Algiers & 36.76 & 3.05 & 25 & Algeria & $\mathrm{TP}$ & ECA\&D \\
\hline 18 & Lyon & 45.75 & 4.84 & 200 & France & $\mathrm{P}$ & ECA\&D \\
\hline 19 & Annaba & 36.82 & 7.81 & 17 & Algeria & $\mathrm{TP}$ & GHCN \\
\hline 20 & Genoa & 44.4 & 8.94 & 2 & Italy & $\mathrm{TP}$ & ECA\&D \\
\hline 21 & Cagliari & 39.24 & 9.11 & 4 & Italy & $\mathrm{P}$ & ECA\&D \\
\hline 22 & Milan & 45.46 & 9.18 & 107 & Italy & $\mathrm{TP}$ & ECA\&D \\
\hline 23 & Mt Cimone & 44.19 & 10.7 & 2165 & Italy & $\mathrm{TP}$ & ECA\&D \\
\hline 24 & Rome & 41.89 & 12.48 & 18 & Italy & $\mathrm{TP}$ & ECA\&D \\
\hline 25 & Aviano & 46.06 & 12.58 & 159 & Italy & $\mathrm{TP}$ & ECA\&D \\
\hline 26 & Tripoli & 32.87 & 13.22 & 11 & Libya & $\mathrm{TP}$ & GHCN \\
\hline 27 & Palermo & 38.11 & 13.35 & 21 & Italy & $\mathrm{TP}$ & ECA\&D \\
\hline 28 & Catania & 37.5 & 15.08 & 11 & Italy & $\mathrm{TP}$ & ECA\&D \\
\hline 29 & Zadar & 44.11 & 15.23 & 82 & Croatia & $\mathrm{TP}$ & ECA\&D \\
\hline 30 & Zagreb & 45.79 & 15.97 & 106 & Croatia & $\mathrm{TP}$ & ECA\&D \\
\hline 31 & Sirte & 31.2 & 16.58 & 7 & Libya & $\mathrm{TP}$ & GHCN \\
\hline 32 & Dubrovnik & 42.56 & 18.24 & 157 & Croatia & $\mathrm{T}$ & ECA\&D \\
\hline 33 & Sarajevo & 43.85 & 18.41 & 511 & $\mathrm{BiH}$ & $\mathrm{TP}$ & ECA\&D \\
\hline 34 & Tirana & 41.32 & 19.81 & 105 & Albania & $\mathrm{TP}$ & ECA\&D \\
\hline 35 & Agedabia & 30.72 & 20.17 & 2 & Libya & $\mathrm{TP}$ & GHCN \\
\hline 36 & Benghazi & 32.08 & 20.27 & 5 & Libya & $\mathrm{TP}$ & GHCN \\
\hline 37 & Kalamata & 37.03 & 22.11 & 6 & Greece & $\mathrm{TP}$ & ECA\&D \\
\hline 38 & Lamia & 38.89 & 22.43 & 87 & Greece & $\mathrm{T}$ & ECA\&D \\
\hline 39 & Thessaloniki & 40.63 & 22.94 & 8 & Greece & $\mathrm{TP}$ & ECA\&D \\
\hline 40 & Heraklion & 35.33 & 25.14 & 37 & Greece & $\mathrm{T}$ & ECA\&D \\
\hline 41 & Siwa & 29.2 & 25.32 & -14 & Egypt & $\mathrm{TP}$ & GHCN \\
\hline
\end{tabular}




\begin{tabular}{lccccccc}
42 & Samos & 37.75 & 26.97 & 2 & Greece & $\mathrm{T}$ & ECA\&D \\
43 & Izmir & 38.43 & 27.17 & 13 & Turkey & $\mathrm{T}$ & GSOD \\
44 & Mersa Matruh & 31.33 & 27.22 & 6 & Egypt & $\mathrm{TP}$ & GHCN \\
45 & Istanbul & 40.98 & 28.82 & 48 & Turkey & $\mathrm{T}$ & GSOD \\
46 & Finike & 36.29 & 30.14 & 3 & Turkey & $\mathrm{T}$ & ECA\&D \\
47 & Antalya & 36.9 & 30.8 & 55 & Turkey & $\mathrm{TP}$ & GHCN \\
48 & Cairo & 30.03 & 31.24 & 64 & Egypt & $\mathrm{P}$ & ECA\&D \\
49 & Nicosia & 35.17 & 33.26 & 91 & Cyprus & $\mathrm{T}$ & ECA\&D \\
50 & Jerusalem & 31.76 & 35.21 & 780 & Israel-Palestine & $\mathrm{TP}$ & ECA\&D \\
51 & Latakia & 35.52 & 35.79 & 7 & Syria & $\mathrm{TP}$ & ECA\&D \\
52 & Tripoli-Leb & 34.45 & 35.82 & 20 & Lebanon & $\mathrm{T}$ & GHCN \\
53 & Sivas & 39.74 & 37.01 & 1285 & Turkey & $\mathrm{T}$ & ECA\&D \\
\hline
\end{tabular}

Table A2. Fractional order (FO) of the twelve versions of the ULMOi for each observatory. From the simulation of the annual precipitation anomaly.

\begin{tabular}{|c|c|c|c|c|c|c|c|c|c|c|c|c|}
\hline & A1 & B1 & $\mathrm{C} 1$ & A2 & B2 & $\mathrm{C} 2$ & $\mathrm{~A} 3$ & B3 & $\mathrm{C} 3$ & A4 & B4 & $\mathrm{C} 4$ \\
\hline A CORUÑA & 9.7 & 12 & 8.2 & 3.4 & 8.2 & 3 & 1 & 4.6 & 2.1 & 1.8 & 5.7 & 2.2 \\
\hline AGEDABIA & 6.5 & 9.9 & 4.1 & 9.6 & 9.5 & 11.4 & 10 & 9.5 & 11.6 & 3.7 & 1 & 5.7 \\
\hline ALGIERS & 8.8 & 12 & 4.2 & 2.2 & 3.2 & 1.3 & 3.4 & 3.5 & 4.2 & 4.8 & 5.3 & 4.6 \\
\hline ANNABA & 4.8 & 1.9 & 11 & 10.9 & 8.6 & 8.5 & 9.8 & 10.8 & 6.9 & 9.1 & 10.2 & 5.4 \\
\hline ANTALYA & 6.5 & 4.9 & 3.7 & 5 & 1 & 6 & 10.7 & 7.1 & 12 & 8.3 & 4.6 & 9.2 \\
\hline AVIANO & 9.5 & 8.8 & 7.7 & 7.4 & 12 & 7.3 & 4.7 & 8.1 & 5.2 & 1 & 3.9 & 1.3 \\
\hline BADAJOZ & 8.1 & 12 & 8.1 & 5.2 & 7.3 & 5.7 & 1 & 2.5 & 2.4 & 2.3 & 4 & 3.2 \\
\hline BARCELONA & 3.3 & 12 & 1.6 & 3.7 & 9.5 & 5.6 & 5.8 & 9.2 & 7.4 & 1.1 & 4.4 & 3.2 \\
\hline BENGHAZI & 5.7 & 2.3 & 9.5 & 10.8 & 11.1 & 8.5 & 11.1 & 11.1 & 10 & 9.4 & 5.1 & 11.4 \\
\hline BILBAO & 11.9 & 8.7 & 6.1 & 5.5 & 10.3 & 1 & 5.4 & 8.9 & 2.7 & 5.2 & 9.5 & 1.5 \\
\hline CAGLIARI & 12 & 10.4 & 6.4 & 8.5 & 5.2 & 5.9 & 6.4 & 1.2 & 5.4 & 6.3 & 1.4 & 4.1 \\
\hline CAIRO & 4.3 & 12 & 2.6 & 2 & 5.8 & 4.5 & 1.5 & 1.2 & 5 & 1 & 3.3 & 3.2 \\
\hline CATANIA & 11.3 & 10.2 & 7 & 9.7 & 5.8 & 5.3 & 7.7 & 1.9 & 4.8 & 7.2 & 1 & 3.1 \\
\hline CEUTA & 8.8 & 12 & 7.7 & 4.7 & 6.2 & 4.5 & 1.7 & 1.1 & 2.1 & 1.6 & 1.6 & 2.4 \\
\hline DUBROVNIK & 8.3 & 5.1 & 11.8 & 8.3 & 10.4 & 5.7 & 3.5 & 5.1 & 1.2 & 4.7 & 6.7 & 1.4 \\
\hline GENOA & 4.5 & 12 & 2.1 & 4.2 & 10 & 4.9 & 5.7 & 10.6 & 7.3 & 2.3 & 7.6 & 3.4 \\
\hline HERAKLION & 7.8 & 8.9 & 4.3 & 7.2 & 4.4 & 9 & 9.8 & 6.7 & 12 & 5.3 & 1 & 6.9 \\
\hline JERUSALEM & 11.9 & 10.2 & 12 & 5.3 & 6.7 & 4.2 & 1.3 & 1.8 & 1 & 5.1 & 5.6 & 4 \\
\hline KALAMATA & 9.3 & 11.9 & 11.2 & 7.9 & 11.2 & 11 & 7.5 & 10.3 & 11.3 & 1 & 2.9 & 6.4 \\
\hline LATAKIA & 10.6 & 12 & 10.4 & 5.7 & 6.7 & 6.5 & 4.2 & 2.3 & 6.8 & 1.5 & 1.5 & 3.2 \\
\hline LISBON & 8.5 & 12 & 8.7 & 6.3 & 8.3 & 6.6 & 1.8 & 3.5 & 2.9 & 1 & 2.9 & 1.9 \\
\hline LYON & 5.1 & 12 & 3.6 & 1.9 & 7.8 & 2.7 & 5.3 & 9.3 & 6.5 & 1.7 & 6.3 & 2.8 \\
\hline MADRID & 6.9 & 12 & 6.3 & 3.1 & 4.7 & 4.3 & 1.4 & 1 & 3.5 & 1.9 & 1.7 & 3.4 \\
\hline MALAGA & 10.9 & 11.4 & 12 & 9 & 8.2 & 9.7 & 5.6 & 2.3 & 6.5 & 4.6 & 1 & 5.6 \\
\hline MELILLA & 7.1 & 2.6 & 4.3 & 7.8 & 1.1 & 8.2 & 10.8 & 4.4 & 12 & 10.6 & 4.5 & 11.4 \\
\hline MERSA-M & 5.9 & 4.3 & 4.8 & 11.1 & 9.2 & 12 & 11.2 & 9.3 & 12 & 5.2 & 1.1 & 7.4 \\
\hline MILAN & 5.7 & 12 & 3.4 & 2.2 & 6.1 & 2.3 & 2.1 & 5 & 3.5 & 1 & 4.1 & 1.7 \\
\hline MT CIMONE & 10.8 & 10 & 6.9 & 5.2 & 3.8 & 3.8 & 7.8 & 6.3 & 7.5 & 8.2 & 6.4 & 7.1 \\
\hline MURCIA & 6.7 & 1 & 6.9 & 9.2 & 4.6 & 10 & 11.9 & 9.2 & 11.4 & 11.6 & 8.4 & 11.8 \\
\hline
\end{tabular}




\begin{tabular}{lcccccccccccc} 
PALERMO & 1 & 5.9 & 5.9 & 7 & 8.9 & 10.4 & 11.8 & 11.8 & 11.1 & 9.3 & 11 & 12 \\
PALMA & 12 & 10.2 & 11.5 & 6.4 & 8 & 1 & 4.4 & 4.4 & 1.1 & 7.1 & 7.9 & 2.8 \\
ROME & 7.4 & 5 & 9.6 & 10.9 & 10.4 & 6.8 & 4 & 5.6 & 1.2 & 7.2 & 9 & 3.6 \\
SARAJEVO & 5.5 & 1 & 6.3 & 12 & 9.1 & 10.4 & 5.5 & 7 & 4.2 & 5.6 & 7.2 & 3.7 \\
SIRTE & 11.7 & 10.3 & 11.3 & 11.2 & 12 & 10.1 & 7.9 & 8.4 & 6.9 & 2.8 & 1 & 1.8 \\
SIWA & 8.2 & 7.3 & 11.5 & 8.7 & 7.5 & 1.1 & 11 & 10.6 & 8.6 & 7 & 2.9 & 11.2 \\
THESSALONIKI & 7.2 & 8.2 & 8.7 & 11.6 & 11.1 & 8 & 8.4 & 4.9 & 3 & 8.6 & 3.4 & 1 \\
TIRANA & 4.8 & 1 & 6.5 & 11.2 & 8.3 & 12 & 7.8 & 9.7 & 6 & 9.4 & 11.5 & 6.7 \\
TOULOUSE & 8 & 12 & 5.7 & 4.1 & 7.1 & 3.6 & 3.8 & 6.4 & 4 & 1.2 & 4.2 & 1.1 \\
TRIPOLI & 12 & 8.3 & 10.8 & 9.3 & 1 & 6.6 & 10.4 & 4 & 8.6 & 10.2 & 11.6 & 11.9 \\
VALENCIA & 3.2 & 1.2 & 4 & 6.3 & 3.4 & 8.9 & 11.4 & 8.8 & 11.7 & 10.7 & 7.6 & 12 \\
ZADAR & 5.2 & 1 & 9.1 & 11.4 & 9.9 & 7.8 & 7.4 & 9.6 & 4.6 & 9.2 & 12 & 6.1 \\
ZAGREB & 8.3 & 1.6 & 11.5 & 8.1 & 12 & 5.1 & 3.5 & 7.1 & 1 & 5.5 & 9 & 2.6 \\
ZARAGOZA & 2.9 & 4.7 & 1 & 5.7 & 4.6 & 7.5 & 9.7 & 8.4 & 12 & 6.4 & 4.3 & 8.4 \\
\hline AVERAGE & 7,6 & 8 & 7,2 & 7,1 & 7,4 & 6,5 & 6,4 & 6,4 & 6,3 & 5,3 & 5,3 & 5,2 \\
\hline
\end{tabular}


Table A3. As Table A2, but for the annual temperature anomaly.

\begin{tabular}{|c|c|c|c|c|c|c|c|c|c|c|c|c|}
\hline & A1 & B1 & $\mathrm{C} 1$ & A2 & B2 & $\mathrm{C} 2$ & A3 & B3 & $\mathrm{C} 3$ & A4 & B4 & $\mathrm{C} 4$ \\
\hline A CORUÑA & 9 & 12 & 4.3 & 2.4 & 4.9 & 1 & 6.1 & 7.5 & 5.7 & 5.8 & 7.8 & 5 \\
\hline AGEDABIA & 9.8 & 12 & 8.5 & 3.6 & 6.1 & 2.7 & 1 & 2.5 & 1.4 & 1.8 & 3.2 & 1.3 \\
\hline ALGIERS & 11.7 & 10.6 & 11.1 & 8.3 & 9 & 3.9 & 5 & 5.1 & 2.2 & 5 & 5.3 & 1 \\
\hline ANNABA & 6 & 7.8 & 11.8 & 9.8 & 8.6 & 3.4 & 5.8 & 3.4 & 1 & 8.3 & 7 & 2.8 \\
\hline ANTALYA & 11.8 & 9.6 & 9.9 & 3.1 & 6.8 & 1.4 & 1.7 & 4.2 & 1.5 & 3.3 & 6.1 & 2.3 \\
\hline AVIANO & 9.5 & 11.7 & 7.7 & 3.8 & 8 & 3.4 & 1.4 & 4.6 & 2.3 & 1.7 & 5.2 & 1.6 \\
\hline BADAJOZ & 6.5 & 5.5 & 1.1 & 3.3 & 1.3 & 3.1 & 10.4 & 9.3 & 11 & 8.8 & 7 & 8.7 \\
\hline BARCELONA & 12 & 9.7 & 8.5 & 6 & 7.8 & 3.9 & 3.5 & 4.5 & 2.2 & 3.4 & 4.6 & 1 \\
\hline BENGHAZI & 9 & 11.9 & 9 & 3.6 & 8.1 & 4.9 & 2.3 & 5.9 & 3.8 & 1 & 4.4 & 2.4 \\
\hline BILBAO & 12 & 10 & 8.8 & 6.6 & 8.1 & 2.9 & 4.8 & 6 & 2.4 & 4.4 & 5.6 & 1 \\
\hline CAGLIARI & 1 & 2.8 & 7.5 & 10.9 & 11.1 & 9.7 & 8.5 & 7.7 & 2.9 & 12 & 11.9 & 7.4 \\
\hline CATANIA & 4.3 & 3 & 5.9 & 11.3 & 9.7 & 11.3 & 3.9 & 5.2 & 1.4 & 7 & 8.7 & 3.5 \\
\hline CEUTA & 12 & 9 & 5 & 6 & 8.5 & 2.1 & 5.7 & 6.3 & 3.3 & 4.9 & 5.3 & 1.8 \\
\hline DUBROVNIK & 2.8 & 2.4 & 2.7 & 9.6 & 8.6 & 12 & 3.9 & 2.8 & 1.9 & 6.6 & 6.2 & 4 \\
\hline FINIKE & 6.5 & 1 & 8.1 & 11 & 10.3 & 9.1 & 7.4 & 9.9 & 5.9 & 11.6 & 8.9 & 10.7 \\
\hline HERAKLION & 9.8 & 3 & 10.8 & 4.9 & 10.4 & 3.2 & 2.8 & 8.3 & 2.4 & 5.6 & 10.4 & 4.3 \\
\hline ISTANBUL & 7.9 & 12 & 5.8 & 1.5 & 4.5 & 1 & 3.7 & 5.5 & 4.3 & 5.2 & 7 & 5.1 \\
\hline IZMIR & 9 & 12 & 9.5 & 3.1 & 7.9 & 4.1 & 1 & 3.7 & 3 & 2.1 & 4.6 & 3.3 \\
\hline JERUSALEM & 8.1 & 5.8 & 8.3 & 10 & 11.5 & 8.6 & 2.6 & 4.2 & 1 & 7.9 & 9.3 & 5.9 \\
\hline KALAMATA & 1.5 & 3.4 & 8.6 & 5.2 & 6.6 & 11.9 & 8.4 & 9.3 & 10.3 & 3 & 2.3 & 11.5 \\
\hline KENITRA & 4.1 & 5.2 & 1 & 7.7 & 6.2 & 7.7 & 11.1 & 11.2 & 11.5 & 10.3 & 9.6 & 10.6 \\
\hline LAMIA & 1 & 10 & 4.9 & 12 & 8.8 & 11.1 & 8.4 & 2.3 & 8 & 11.1 & 7.6 & 10.3 \\
\hline LATAKIA & 3.6 & 2.4 & 3.9 & 10.5 & 9.3 & 10.3 & 2.7 & 2.3 & 1 & 9.5 & 9.5 & 8.2 \\
\hline LISBON & 5.9 & 10.1 & 3.2 & 2.5 & 4.6 & 1 & 7.7 & 9.2 & 8 & 5.4 & 6.7 & 4.9 \\
\hline MADRID & 6.4 & 12 & 1.4 & 1.3 & 3.8 & 1.5 & 4.9 & 6.3 & 6.1 & 1.5 & 2.8 & 2.4 \\
\hline MALAGA & 8.7 & 2.5 & 7.2 & 9.7 & 7.7 & 9.4 & 8.9 & 9.3 & 9.5 & 8.4 & 5.2 & 7.5 \\
\hline MELILLA & 11.1 & 11.5 & 5.3 & 4.7 & 3.8 & 1 & 6.9 & 6.7 & 5.6 & 5.8 & 5 & 2.9 \\
\hline MERSA-M & 8.9 & 12 & 7 & 2 & 5.8 & 1.1 & 1.3 & 3.9 & 1.9 & 2.9 & 5.6 & 2.7 \\
\hline MILAN & 11.4 & 9.2 & 11 & 5.9 & 10.9 & 5 & 2.3 & 6.5 & 1.9 & 3.9 & 7.2 & 2.5 \\
\hline MT CIMONE & 5.3 & 1.1 & 8.5 & 11.7 & 11.4 & 7.8 & 4.1 & 6.3 & 1.1 & 6.7 & 9.2 & 3.4 \\
\hline MURCIA & 11.1 & 11.9 & 8 & 6.9 & 7.6 & 4.3 & 5.9 & 6 & 4.1 & 3.7 & 3.8 & 1 \\
\hline NICOSIA & 6.7 & 2.4 & 6.9 & 9.2 & 11.9 & 6.4 & 2.6 & 6.1 & 1.5 & 9.8 & 12 & 7.7 \\
\hline PALERMO & 3.2 & 1 & 6.9 & 9.4 & 8 & 10.9 & 11.3 & 10.9 & 10.4 & 11.3 & 10.9 & 9.7 \\
\hline PALMA & 11.9 & 9.8 & 8.5 & 5.5 & 7 & 2.3 & 2.6 & 3.7 & 1 & 4.2 & 5.5 & 1.6 \\
\hline PERPIGNAN & 12 & 11.1 & 8.1 & 5.5 & 7 & 2.8 & 3.3 & 4.2 & 1.8 & 3.8 & 4.7 & 1 \\
\hline ROME & 1.3 & 1.6 & 2.2 & 7.6 & 6.9 & 9.5 & 11.4 & 11.5 & 9.8 & 10.6 & 10.3 & 11.3 \\
\hline SAMOS & 5.2 & 1 & 6.1 & 8.5 & 11.3 & 4.3 & 9.9 & 11.7 & 8.4 & 8 & 4.3 & 10.9 \\
\hline SARAJEVO & 2.3 & 6.2 & 1 & 2.6 & 3.9 & 4.7 & 9.2 & 10.4 & 11.6 & 9.4 & 10.9 & 12 \\
\hline SIRTE & 6 & 11.7 & 3.5 & 1.5 & 2.5 & 3.7 & 7.1 & 6.6 & 9 & 6.4 & 6.5 & 7.5 \\
\hline SIVAS & 6.6 & 3.4 & 8.7 & 9 & 10.6 & 6.5 & 4.2 & 5.4 & 1.3 & 11.2 & 11.8 & 9.2 \\
\hline SIWA & 11.9 & 11.9 & 8.5 & 4.4 & 6.2 & 3.7 & 1.5 & 2.2 & 1.1 & 2.9 & 3.6 & 1.8 \\
\hline THESSALONIKI & 3.7 & 6.5 & 6.8 & 1 & 4.6 & 7.1 & 5.7 & 8.4 & 12 & 3.6 & 6.3 & 10.3 \\
\hline
\end{tabular}




\begin{tabular}{lcccccccccccc} 
TIRANA & 1.4 & 7.9 & 2.1 & 2.4 & 7 & 5.8 & 11 & 11.5 & 12 & 11.3 & 11 & 11.8 \\
TOULOUSE & 12 & 8.4 & 10.8 & 6.6 & 8.2 & 3.5 & 3.4 & 4 & 1 & 4.8 & 6.4 & 1.8 \\
TRIPOLI & 12 & 11.3 & 9.9 & 5.5 & 7.5 & 3.6 & 2 & 2.1 & 1.4 & 6.7 & 8 & 5.4 \\
TRIPOLI-LEB & 6.7 & 12 & 4.5 & 1.2 & 4.2 & 1.4 & 1.2 & 2.7 & 2.3 & 1.2 & 2.8 & 1.4 \\
VALENCIA & 12 & 10.2 & 7.5 & 5 & 1.3 & 2.3 & 5.4 & 1.5 & 4.1 & 5.2 & 1.5 & 3.1 \\
ZADAR & 2.6 & 1 & 3.8 & 10.2 & 8.8 & 11.9 & 5.2 & 5.2 & 3.5 & 9 & 9.4 & 6.6 \\
ZAGREB & 2.3 & 1 & 4 & 9.1 & 7.4 & 12 & 9.3 & 9.8 & 7.5 & 10.8 & 11.7 & 7.9 \\
ZARAGOZA & 11.2 & 12 & 6.2 & 4.9 & 4.3 & 2.5 & 4.2 & 3 & 3 & 3.4 & 2 & 1 \\
\hline AVERAGE & 7,2 & 7,4 & 6,6 & 6,2 & 7,5 & 5,4 & 5,4 & 6,5 & 4,8 & 6,3 & 7 & 5,5 \\
\hline
\end{tabular}

Figures \& Figure Captions

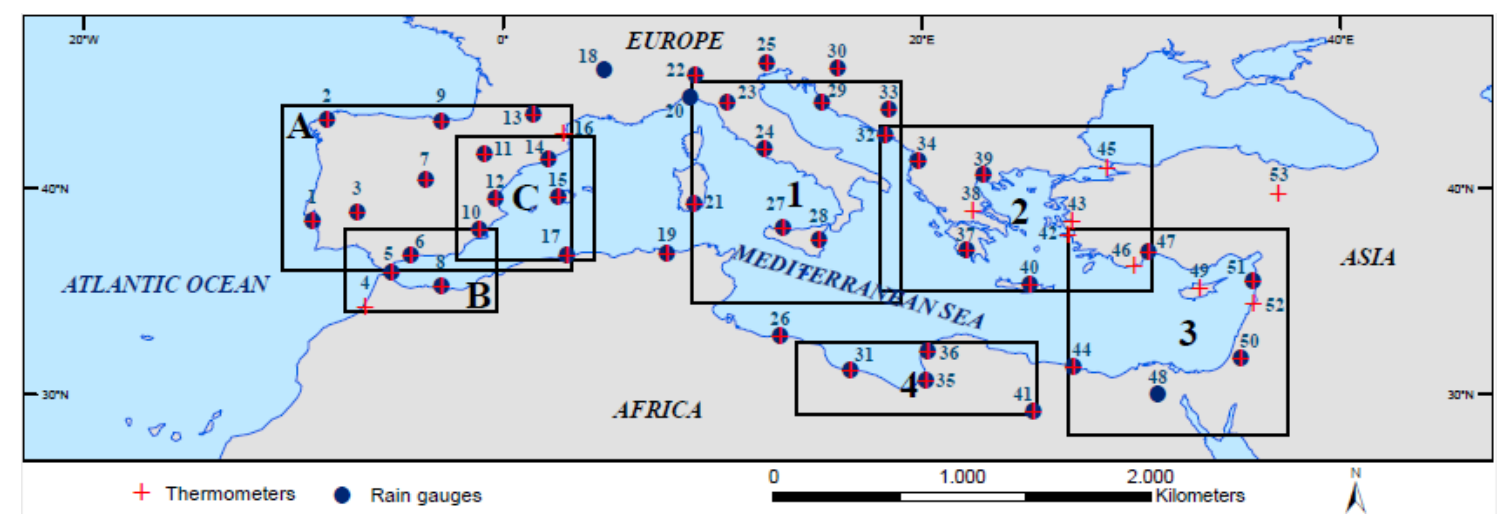

Figure 1. Distribution of windows and meteorological observatories (points enumerated in Table A1) along the Mediterranean basin used in the study.

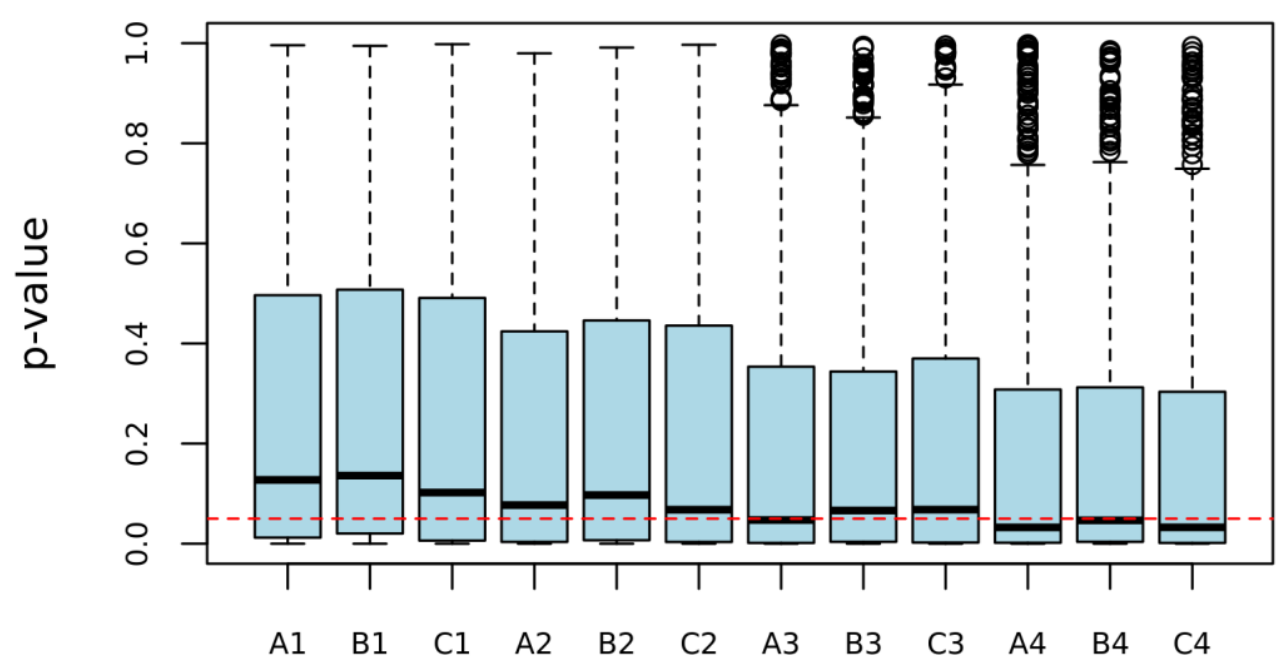


Figure 2. Pearson correlation $p$-value of monthly precipitation simulated and observed for each combination of windows. The lines of the box correspond to the first, second, and third quartiles. The dashed lines represent 1.5 times the interquartile range. The dashed red line indicates the threshold for $p$-value $=0.05$.

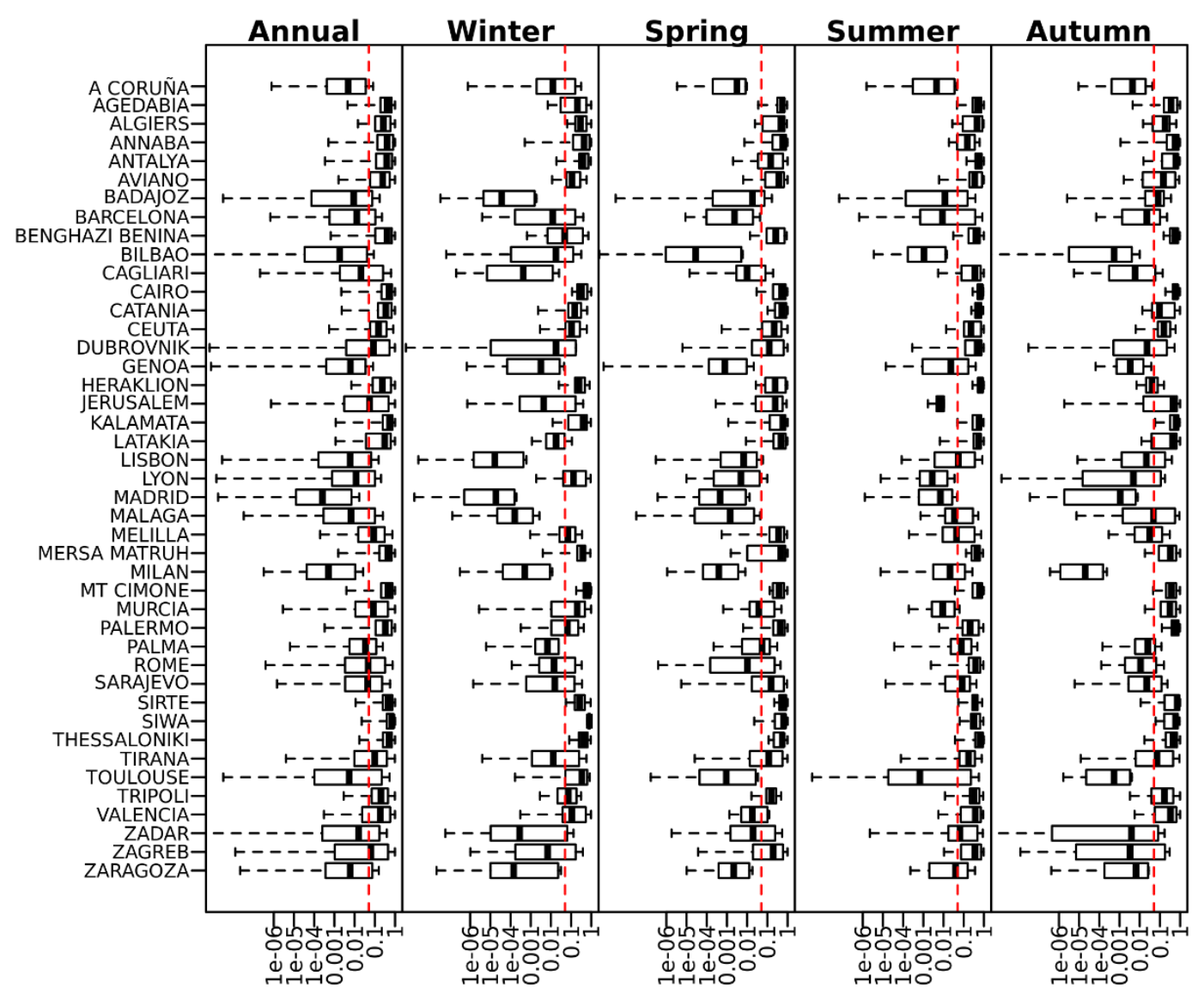

Figure 3. Pearson correlation $p$-value obtained comparing seasonal simulation from the studied indices and the observed anomaly in rainfall. The lines of the box correspond to the first, second, and third quartiles, while the dashed lines represent 1.5 times the interquartile range. The dashed red line indicates the threshold for $p$-value $=0.05$. 


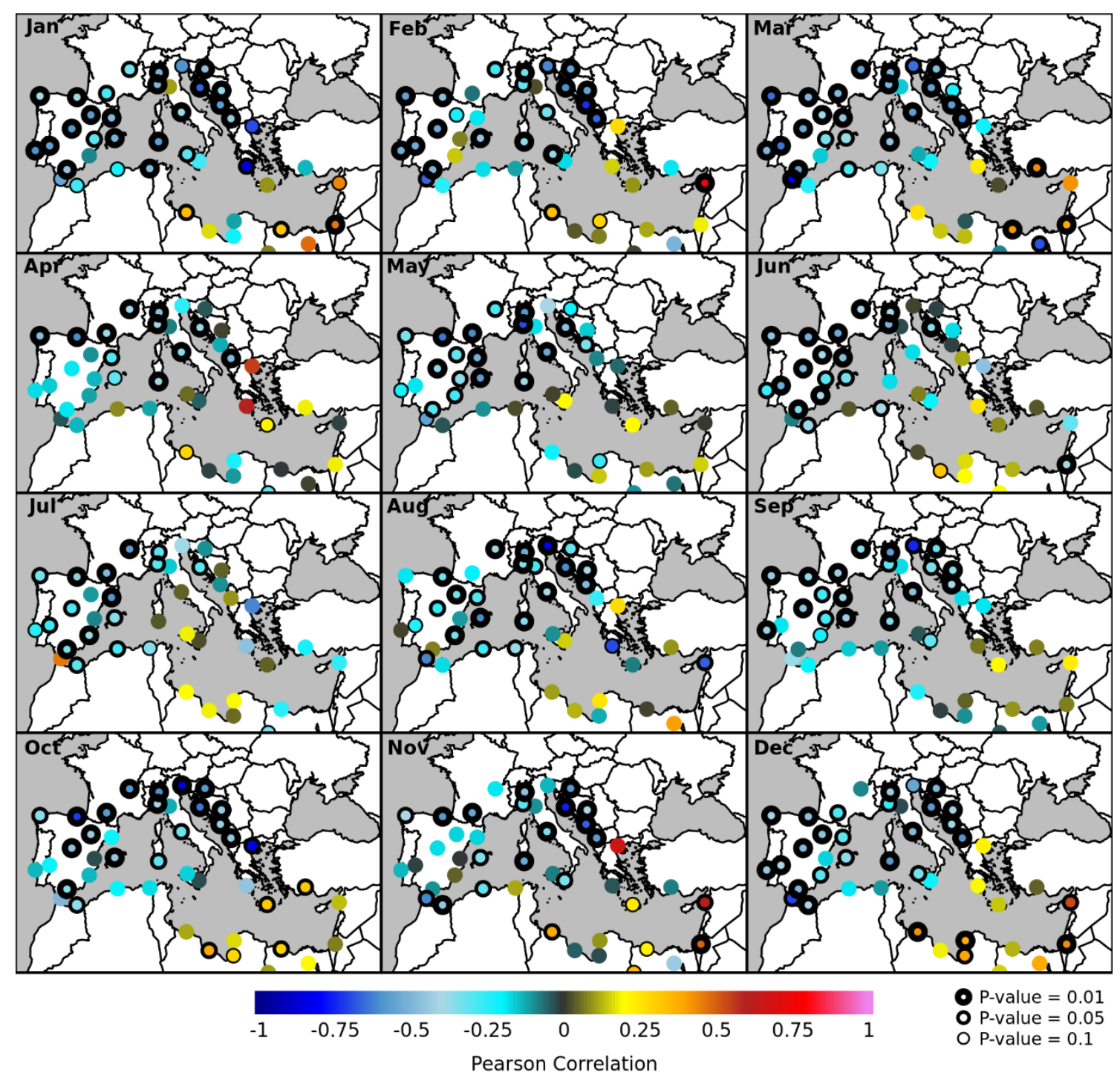

Figure 4. Spatial distribution of the Pearson correlation obtained comparing simulated and observed precipitation for each month of the year, from January to December, from left to right, and from top to bottom. The bold edges of the circles indicate cases with statistical significance for correlation according to several $p$-values $(0.01,0.05$, and 0.1$)$. 


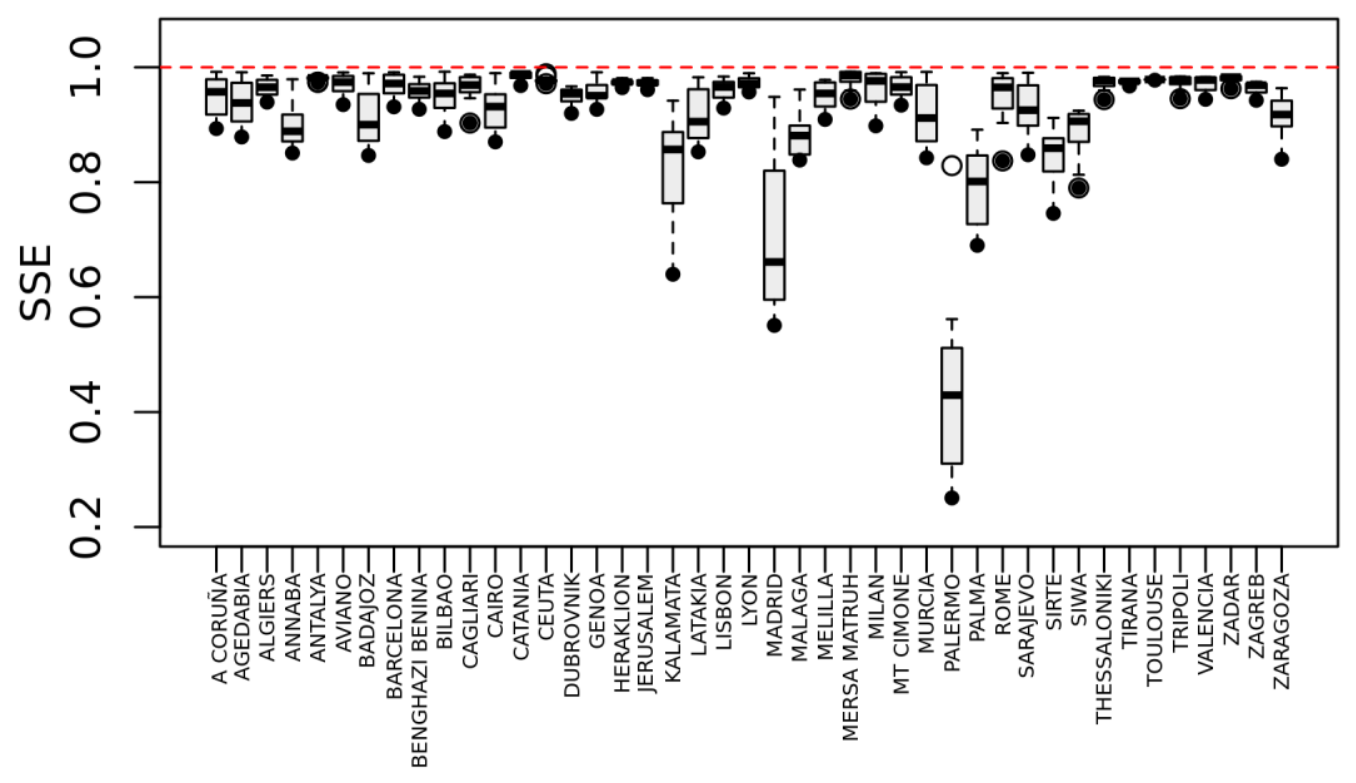

Figure 5. Standardized mean squared error (SSE) of the precipitation prediction using the ULMOi C4 calculated for each month of the year and each observatory. The lines of the box correspond to the first, second, and third quartiles, while the dashed lines represent 1.5 times the interquartile range. The dashed red line indicates the threshold for SSE $=1$.

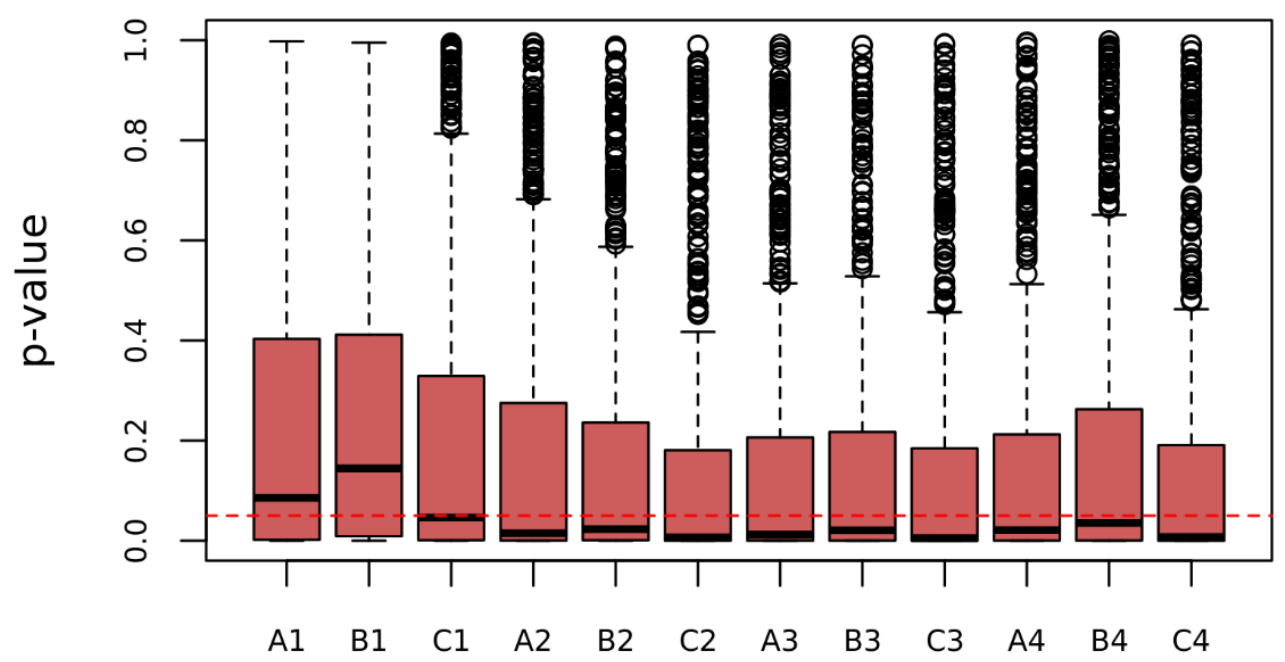

Figure 6. Same as Figure 2, but for monthly temperature. 


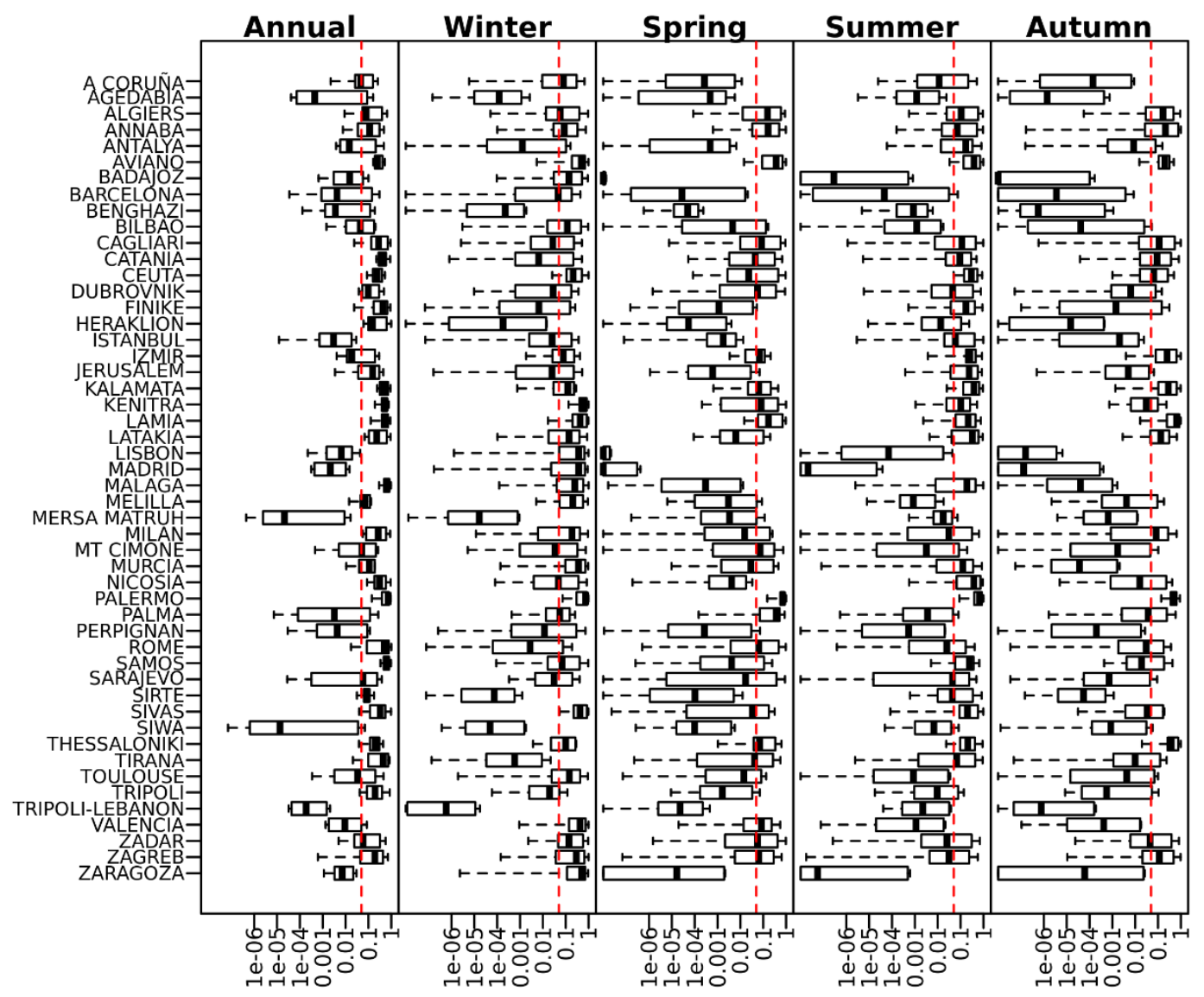

Figure 7. Same as Figure 3, but comparing monthly simulation for temperature. 


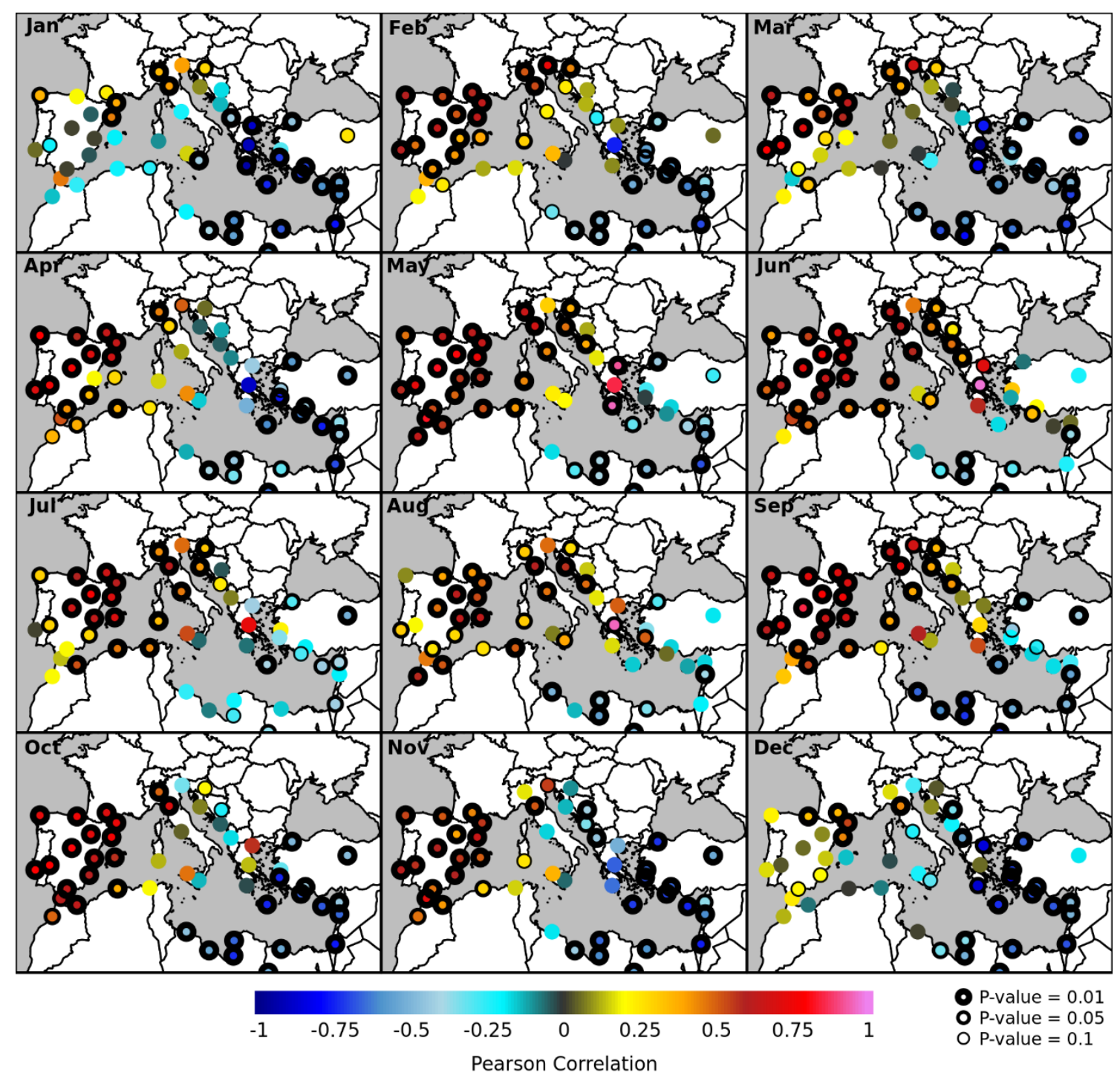

Figure 8. Same as Figure 4, but comparing monthly simulation from ULMOi C3 and the observed anomaly in temperature.

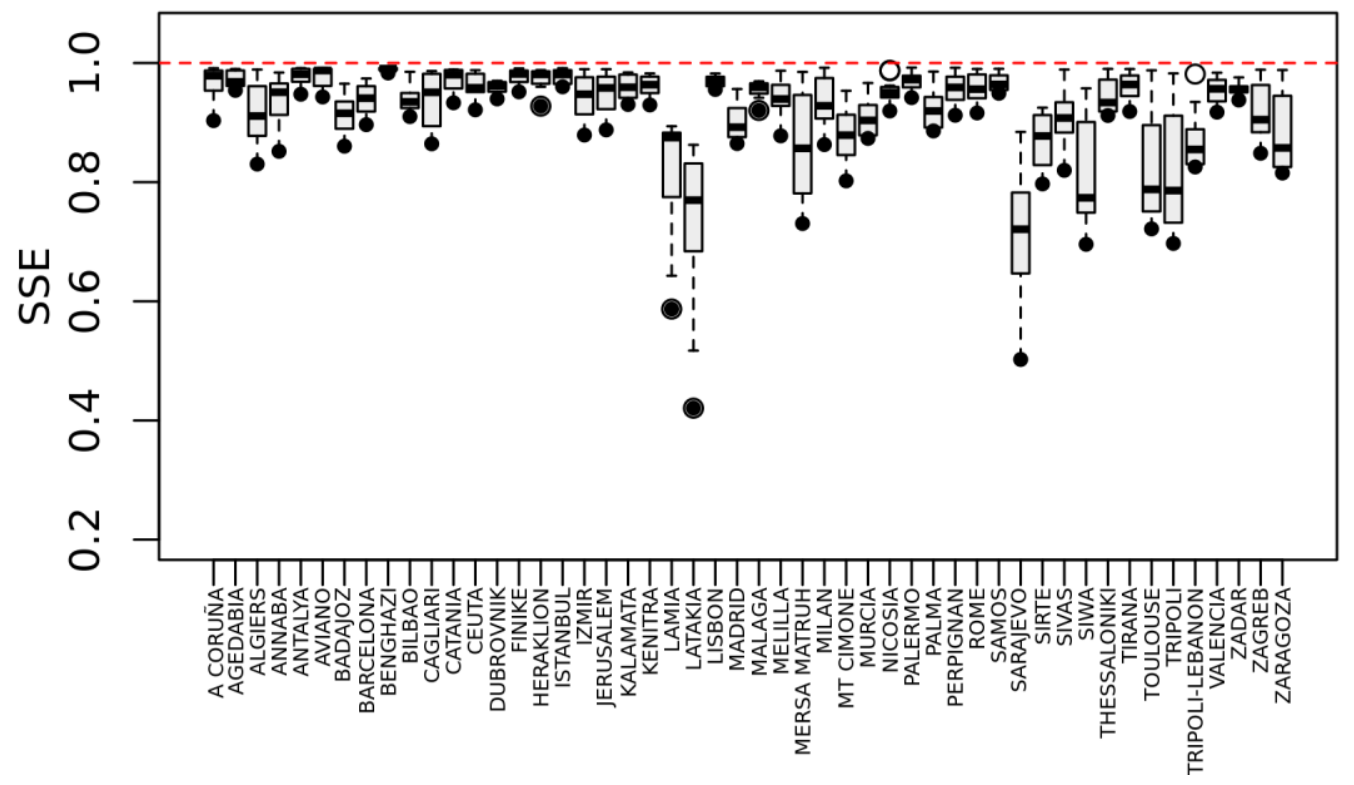


Figure 9. Same as Figure 5, but for temperature and ULMOi C3.
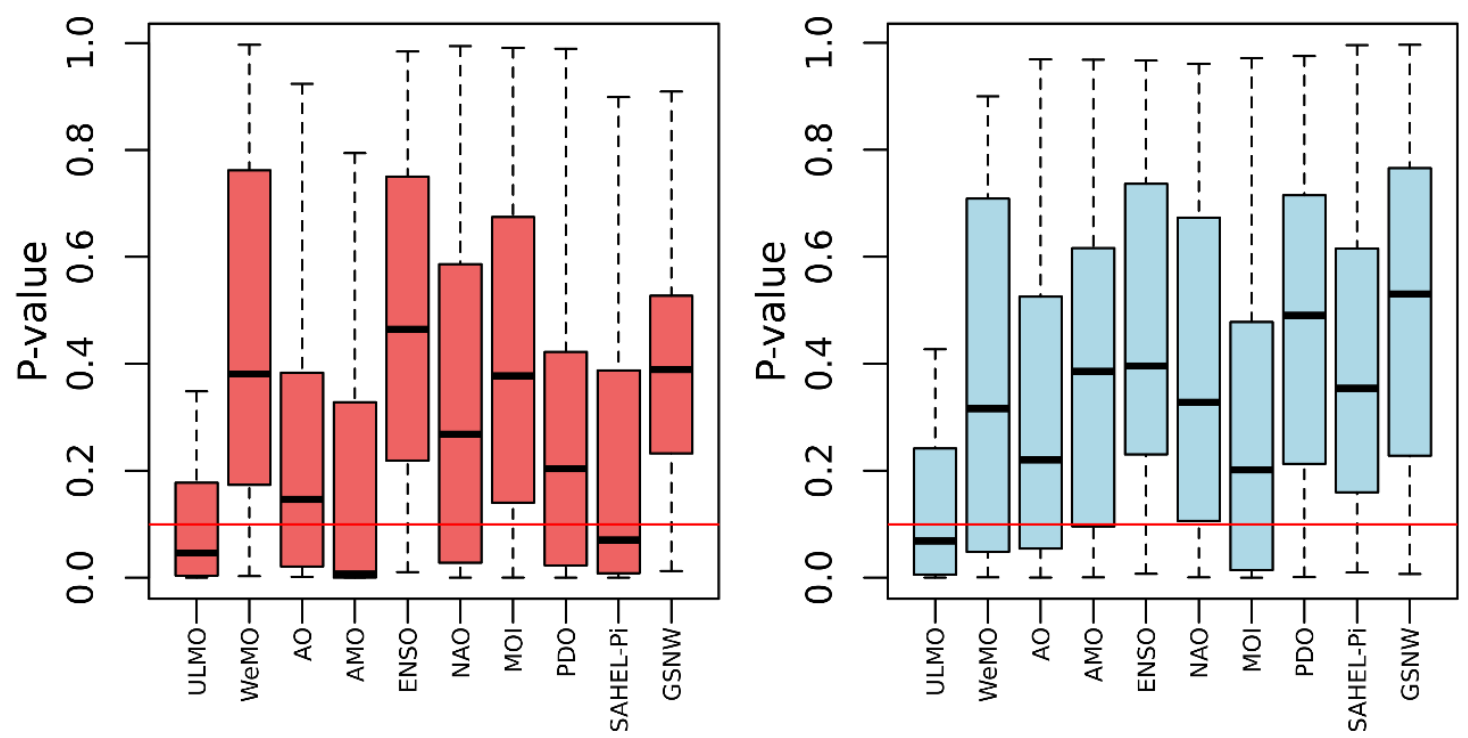

Figure 10. Pearson correlation p-value for each index and all stations, with respect to the annual temperature anomaly (left) and precipitation (right). Lines of boxplot correspond to the first, second, and third quartiles, while the dashed lines represent 1.5 times the interquartile range. The dashed red line indicates the threshold for $p$-value $=0.1$. 

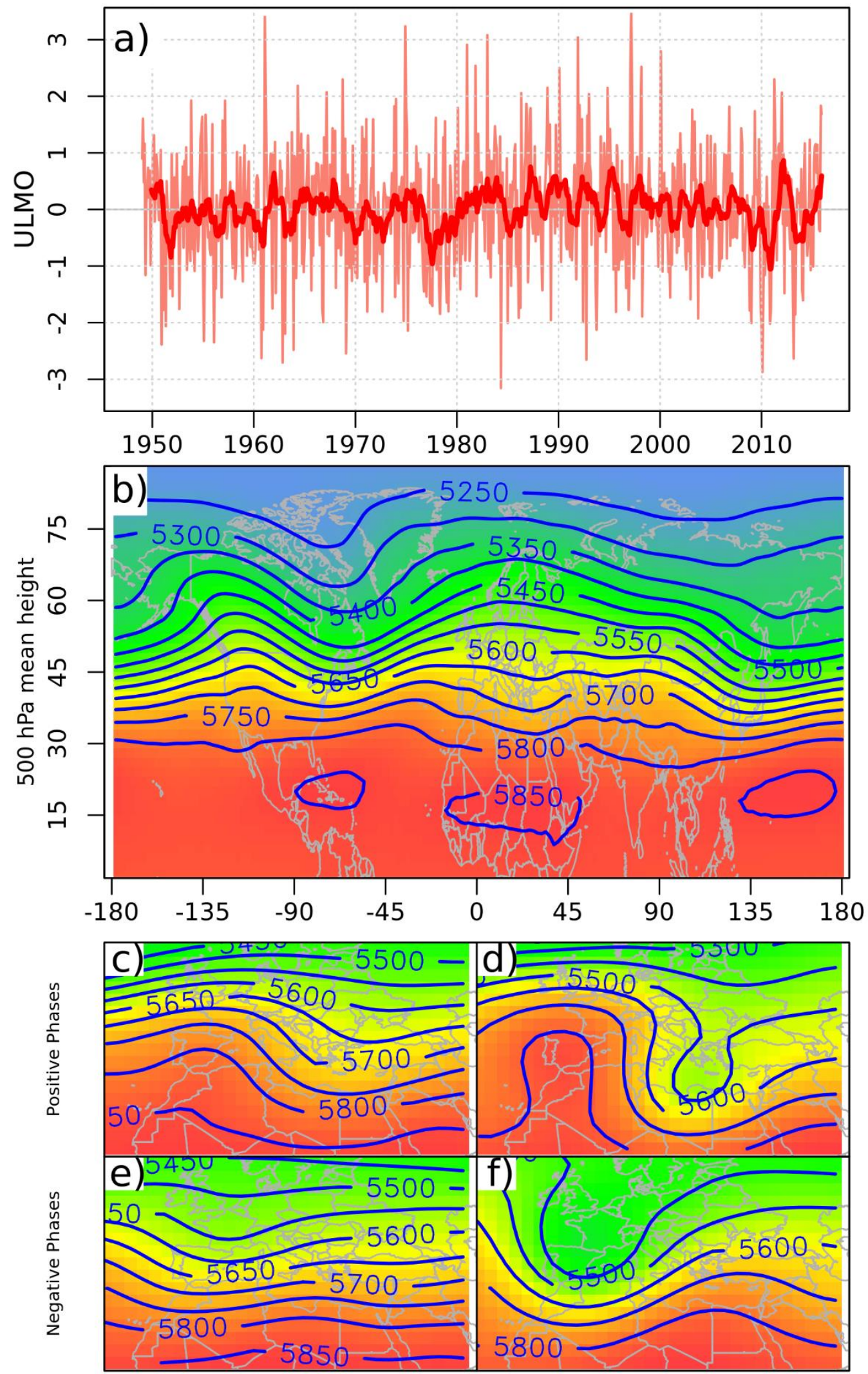

Figure 11. Evolution of monthly ULMOi C4 normalized with standard deviation (light red) and 12 months moving average (dark red) (11a). ULMO-C4 phases: average (11b), positive $0.5<\mathrm{ULMOi}<1.5$ (11c) and ULMOi>3 (11d), negative $-1.5<\mathrm{ULMO}<-0.5$ (11e) and ULMOi<-3 (11f). 


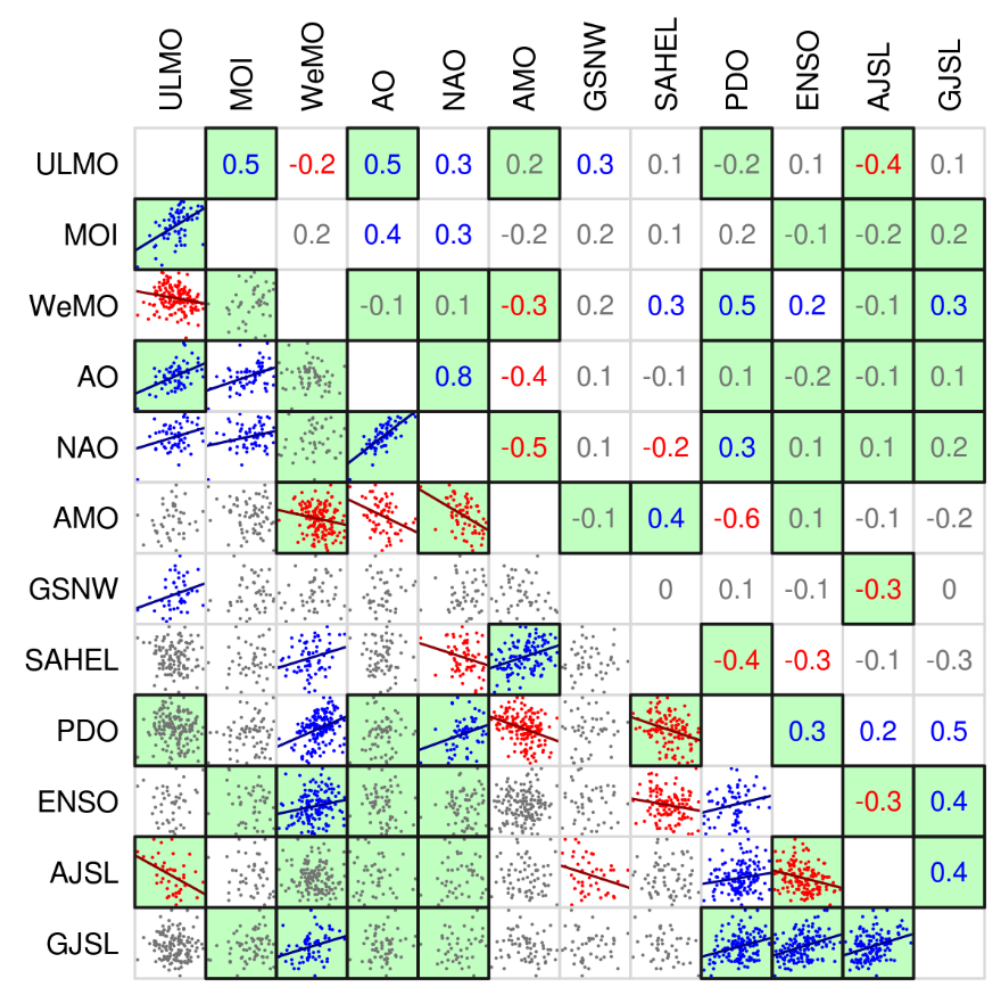

Figure 12. Pearson correlation coefficients (top right) and scatter plots (bottom left) between the analyzed indices, including the two measures of the jet stream latitude variability (GJSL and AJSL) shown in green. Trend lines are shown only for cases with significant $(<0.05)$ positive (blue) and negative (red) correlation. 